\title{
Efficacy and Safety of Budesonide and Formoterol in One Pressurized Metered-Dose Inhaler in Patients with Moderate to Very Severe Chronic Obstructive Pulmonary Disease
} Results of a 6-Month Randomized Clinical Trial

\author{
Donald P. Tashkin, ${ }^{1}$ Stephen I. Rennard, ${ }^{2}$ Paula Martin, ${ }^{3}$ Sulabha Ramachandran, ${ }^{3}$ \\ Ubaldo J. Martin, 3 Philip E. Silkoff 3 and Mitchell Goldman ${ }^{3}$ \\ 1 Division of Pulmonary and Critical Care Medicine, University of California, Los Angeles, \\ California, USA \\ 2 University of Nebraska Medical Center, Omaha, Nebraska, USA \\ 3 AstraZeneca LP, Wilmington, Delaware, USA
}

\section{Abstract}

Background: The combination of an inhaled corticosteroid (ICS) and a longacting bronchodilator is recommended in the treatment of patients with chronic obstructive pulmonary disease (COPD) who have frequent exacerbations. Budesonide/formoterol dry powder inhaler (DPI) has demonstrated efficacy and tolerability in patients with COPD.

Objective: To evaluate the efficacy and tolerability of budesonide/formoterol administered via one hydrofluoroalkane pressurized metered-dose inhaler (pMDI) in patients with COPD.

Methods: This was a 6-month, randomized, double-blind, double-dummy, placebo-controlled, parallel-group, multicentre study (NCT00206154) of 1704 patients aged $\geq 40$ years with moderate to very severe COPD conducted in 194 centres in the US, Czech Republic, the Netherlands, Poland and South Africa. After 2 weeks of treatment based on previous therapy (ICSs and short-acting bronchodilators allowed during the run-in period), patients received one of the following treatments administered twice daily: budesonide/formoterol pMDI 160/4.5 $\mu \mathrm{g} \times$ two inhalations $(320 / 9 \mu \mathrm{g})$; budesonide/formoterol pMDI 80/4.5 $\mu \mathrm{g} \times$ two inhalations $(160 / 9 \mu \mathrm{g})$; budesonide pMDI $160 \mu \mathrm{g} \times$ two inhalations $(320 \mu \mathrm{g})$ plus formoterol DPI $4.5 \mu \mathrm{g} \times$ two inhalations $(9 \mu \mathrm{g})$; budesonide pMDI $160 \mu \mathrm{g} \times$ two inhalations $(320 \mu \mathrm{g})$; formoterol DPI $4.5 \mu \mathrm{g} \times$ two inhalations $(9 \mu \mathrm{g})$; or placebo.

Main outcome measures: The co-primary efficacy variables were pre-dose forced expiratory volume in 1 second $\left(\mathrm{FEV}_{1}\right)$ and 1-hour post-dose $\mathrm{FEV}_{1}$.

Results: Budesonide/formoterol 320/9 $\mu \mathrm{g}$ demonstrated significantly greater improvements in pre-dose $\mathrm{FEV}_{1}$ versus formoterol $(\mathrm{p}=0.026$; pre-specified primary comparator) and 1-hour post-dose $\mathrm{FEV}_{1}$ versus budesonide $(\mathrm{p}<0.001$; 
pre-specified primary comparator); budesonide/formoterol 160/9 $\mu \mathrm{g}$ demonstrated significantly greater improvements versus budesonide $(\mathrm{p}<0.001)$ for 1 -hour post-dose $F_{E V}$ but not versus formoterol for pre-dose FEV 1 . Dyspnoea (measured using the Breathlessness Diary) and health-related quality-of-life (HRQOL) scores (based on the St George's Respiratory Questionnaire total score) were significantly improved with both dosage strengths of budesonide/formoterol compared with budesonide, formoterol and placebo ( $\mathrm{p} \leq 0.044$ for all). Although not powered a priori for comparisons, the number of exacerbations per patienttreatment year requiring treatment with oral corticosteroids and/or hospitalization was numerically $(20-25 \%)$ lower with the budesonide-containing treatments (0.710-0.884) versus formoterol (1.098) and placebo (1.110). This result was driven by the exacerbations requiring treatment with oral corticosteroids (79-120 events). The number of exacerbations resulting in hospitalization was very low across treatment groups (11-22); the number per patient-treatment year was significantly different for budesonide/formoterol 320/9 $\mu \mathrm{g}(0.158)$ versus other treatment groups (0.081-0.108) except budesonide/formoterol 160/9 $\mu \mathrm{g}(0.139)$, and for budesonide/formoterol 160/9 $\mu$ g versus formoterol (0.081) [p $\leq 0.05]$. All treatments were generally well tolerated. The incidence of individual non-fatal serious adverse events was similar across all treatment groups, except COPD, which was highest in the budesonide/formoterol 320/9 $\mu \mathrm{g}$ group (6.1\%) and lowest in the budesonide (3.6\%) and formoterol (3.9\%) groups, with a range of $4.3-4.6 \%$ in the budesonide/formoterol $160 / 9 \mu \mathrm{g}$, budesonide plus formoterol and placebo groups. Budesonide/formoterol had a safety profile comparable with that of the monocomponents and placebo. There was no increase in the incidence of pneumonia in the active treatment groups relative to placebo.

Conclusions: Budesonide/formoterol pMDI 320/9 $\mu \mathrm{g}$ demonstrated significantly greater efficacy for pulmonary function on both co-primary endpoints versus the pre-specified comparators (formoterol DPI $9 \mu \mathrm{g}$ for pre-dose $\mathrm{FEV}_{1}$ and budesonide pMDI $320 \mu \mathrm{g}$ for 1-hour post-dose $\mathrm{FEV}_{1}$ ). Budesonide/formoterol pMDI $160 / 9 \mu \mathrm{g}$ demonstrated significantly greater efficacy for 1-hour post-dose FEV 1 versus budesonide pMDI $320 \mu \mathrm{g}$. Dyspnoea scores and HR-QOL were significantly improved with both budesonide/formoterol pMDI dosage strengths versus both monocomponents and placebo. Both budesonide/formoterol pMDI dosage strengths were well tolerated relative to the monocomponents and placebo.

\section{Background}

Chronic obstructive pulmonary disease (COPD) is characterized by progressive fixed airflow limitation and an abnormal inflammatory response to noxious stimuli. ${ }^{[1]}$ The goals of COPD therapy include (i) improvements in airflow, exercise tolerance, health status and COPD symptoms (e.g. dyspnoea); (ii) prevention of disease progression and exacerbations; and (iii) a reduction in mortality. ${ }^{[1]}$
In patients with COPD, long-acting $\beta_{2}$-adrenoceptor agonists (LABAs) have been shown to achieve several of these therapeutic goals, including improvement in pulmonary function and COPD symptoms, reduction in rescue medication use and improvement in health-related quality of life (HRQOL) ${ }^{[2-6]}$ Inhaled corticosteroids (ICSs) reduce the frequency of exacerbations, ${ }^{[7-9]}$ but have shown inconsistent results in terms of reduction in mortality and modest effects with respect to improvement in pulmonary function. ${ }^{[9-16]}$ 
The combination of the ICS budesonide and the LABA formoterol administered in a single dry powder inhaler (DPI) [Symbicort ${ }^{\circledR}$ Turbuhaler ${ }^{\circledR} ;{ }^{1}$ AstraZeneca, Lund, Sweden] demonstrated significant improvements in pulmonary function, HR-QOL and symptoms, and a significant reduction in exacerbation rate compared with placebo in patients with COPD. ${ }^{[17,18]}$ Moreover, in comparison with the monocomponents, budesonide/formoterol DPI demonstrated significant improvements in forced expiratory volume in 1 second $\left(\mathrm{FEV}_{1}\right)$ versus budesonide alone ${ }^{[17,18]}$ and formoterol alone, ${ }^{[17]}$ and a significant reduction in the rate of severe and overall COPD exacerbations compared with formoterol alone. ${ }^{[17,18]}$

The present 6-month study evaluated the efficacy and tolerability of budesonide/formoterol administered via a hydrofluoroalkane (HFA) pressurized metered-dose inhaler (pMDI) [Symbicort ${ }^{\circledR}$ pMDI; AstraZeneca, Charnwood, Loughborough, UK] in patients with moderate to very severe COPD. Budesonide/formoterol pMDI was administered in two dosage strengths $(160 / 4.5 \mu \mathrm{g} \times$ two inhalations [320/9 $\mu \mathrm{g}]$ and 80/4.5 $\mu \mathrm{g} \times$ two inhalations [160/ $9 \mu \mathrm{g}]$ ), each administered twice daily, and compared with the monocomponents (administered alone or in combination via separate inhalers) and placebo. This is the first time that two doses of budesonide in combination with a LABA have been evaluated in the same study in patients with COPD, the results of which may provide some insight into the efficacy and safety implications of differing doses of ICS in combination with a LABA in clinical practice.

\section{Patients and Methods}

\section{Patients}

The inclusion criteria were designed to enrol patients with moderate to very severe COPD who had previous exacerbations and were therefore suitable candidates for ICS/LABA combination therapy. Current or ex-smokers aged $\geq 40$ years with a clinical diagnosis of COPD and symptoms for $>2$ years were eligible for this study. Patients were required to have a history of at least one COPD exacerbation treated with a course of oral corticosteroids and/or antibacterials within 1-12 months before screening (visit 1) and documented use of an inhaled short-acting bronchodilator as rescue medication. At screening, spirometry was performed before and 15-30 minutes after administration of two inhalations of salbutamol (albuterol) pMDI (total dose 180-200 $\mu \mathrm{g}$ ). A prebronchodilator $\mathrm{FEV}_{1}$ of $\leq 50 \%$ of predicted normal and a prebronchodilator $\mathrm{FEV}_{1} /$ forced vital capacity of $<70 \%$ were required at screening. Additional criteria included a smoking history of $\geq 10$ pack-years, a score of $\geq 2$ on the Modified Medical Research Council dyspnoea scale at the time of screening, ${ }^{[19]}$ and a breathlessness, cough and sputum scale (BCSS) score of $\geq 2$ per day for at least half of the 2-week run-in period.

Patients were excluded if they had any of the following conditions: (i) a history of asthma; (ii) a history of allergic rhinitis before 40 years of age; (iii) significant/unstable cardiovascular disorder; (iv) clinically significant respiratory tract disorder other than COPD; and (v) homozygous $\alpha-1$ antitrypsin deficiency or any other clinically significant comorbidities that could preclude participation in the study or interfere with the study results, as determined by the investigator. Patients were also excluded if they needed additions or alterations to their usual COPD maintenance therapy or an increment in rescue therapy due to worsening symptoms within 30 days before screening or during the run-in period. Oral or ophthalmic non-cardioselective $\beta$ adrenoceptor antagonists, oral corticosteroids, pregnancy and breast-feeding also were exclusionary.

\section{Study Design and Treatment}

This randomized, double-blind, double-dummy, placebo-controlled, parallel-group, 6-month study (NCT00206154) was conducted in 194 centres in the US, Czech Republic, the Netherlands, Poland and South Africa. The study consisted of a screening visit (visit 1), a 2-week run-in period, a randomization visit (visit 2), four subsequent visits during the

1 The use of trade names is for product identification purposes only and does not imply endorsement. 


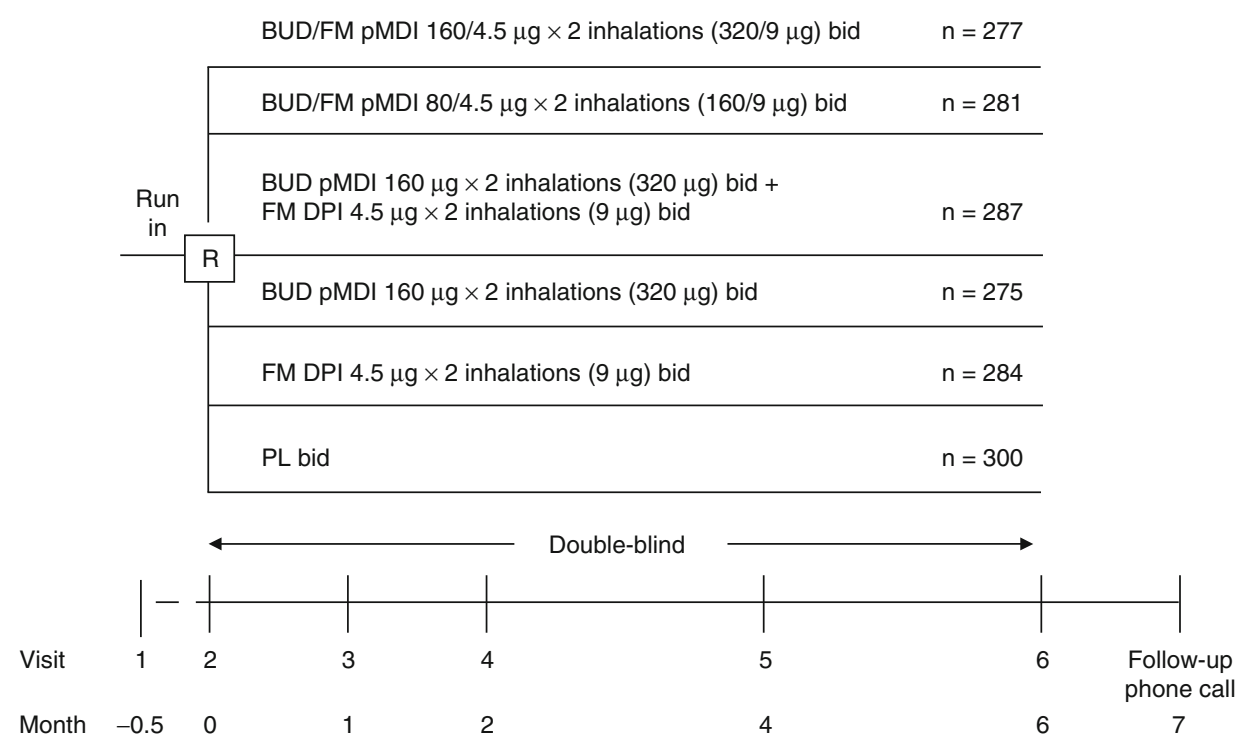

Fig. 1. Study design. To maintain blinding, patients received both a pressurized metered-dose inhaler (pMDI) and a dry powder inhaler (DPI) containing either active treatment or placebo (PL), or combinations of active treatment and placebo, as appropriate. bid = twice daily; BUD = budesonide; $\mathbf{F M}=$ formoterol; $\mathbf{R}=$ randomization.

26-week treatment period and a follow-up telephone call 30 days after the last study visit. During the 2-week run-in period, patients continued ICS monotherapy if they had previously been receiving ICS alone or in combination with a LABA, and patients who had previously been receiving anticholinergic therapies were placed on stable doses of ipratropium bromide. A short-acting $\beta_{2}$-adrenoceptor agonist was allowed for rescue use. At visit 2 (after the runin period), any ICS therapy was discontinued and all patients were then given study rescue medication (salbutamol pMDI) for as-needed use.

At visit 2, eligible patients were randomized in balanced blocks according to a computer-generated randomization scheme at each site to one of six treatments administered twice daily (figure 1). The present study used formoterol DPI (formoterol Turbuhaler ${ }^{\circledR}$; AstraZeneca, Södertälje, Sweden) as the formoterol comparator rather than formoterol pMDI. Results from a previous study in patients with asthma demonstrated equivalent formoterolrelated bronchodilation when formoterol was administered in combination with budesonide via pMDI or alone via DPI. ${ }^{[20]}$ Budesonide was administered via an HFA pMDI (budesonide pMDI; Astra-
Zeneca, Charnwood, Loughborough, UK). Visits 3-6 were scheduled at 1,2, 4 and 6 months after randomization. Salbutamol was not to be used within 6 hours before each clinic visit; inhaled ipratropium bromide was not to be used within 8 hours before each clinic visit. Allowed and disallowed concomitant medications are described in table I.

The study protocol was approved by a review board and ethics committee at each site, and written informed consent was obtained from patients. The study was performed in accordance with the ethical principles based on the Declaration of Helsinki and consistent with the International Conference on Harmonization/Good Clinical Practice and applicable local regulatory requirements.

\section{Efficacy Evaluations}

The co-primary efficacy variables were pre-dose $\mathrm{FEV}_{1}$ and 1-hour post-dose $\mathrm{FEV}_{1}$, measured at all clinic visits. Spirometry was performed according to American Thoracic Society guidelines. ${ }^{[21]}$ Spirometry measurements were performed in the morning at approximately the same time ( \pm 1 hour) at each clinic visit, approximately 12 hours after the previous dose 
of study medication. Crapo-predicted normals ${ }^{[22]}$ for $\mathrm{FEV}_{1}$ were used.

Secondary pulmonary function variables included 12-hour spirometry, pre-dose and 1-hour postdose inspiratory capacity (IC), and morning and evening peak expiratory flow (PEF). Twelve-hour serial $\mathrm{FEV}_{1}$ was performed in a subset of patients $(\mathrm{n}=618)$ pre-dose and at $5,15,30,60,120,180$, $240,360,480,600$ and 720 minutes after administration of study medication at randomization, and months 2 and 6. Baseline-adjusted average 12-hour $\mathrm{FEV}_{1}$ (calculated as the area between the 12-hour post-dose $\mathrm{FEV}_{1}$ over time curve and the baseline pre-dose $\mathrm{FEV}_{1}$ [defined as the last pre-dose $\mathrm{FEV}_{1}$ before the first dose of randomized treatment] divided by the observation time), $\mathrm{FEV}_{1}$ at 12 hours and maximum $\mathrm{FEV}_{1}$ were determined. Pre-dose and 1hour post-dose IC were assessed in this subset of patients. Morning and evening PEF were measured daily before administration of the morning and evening dose of study medication using a MiniWright ${ }^{\circledR}$ peak flow metre (Clement Clark, Inc., Harlow, UK), and the highest of three measurements was recorded by patients in their diary cards.

Secondary efficacy variables included dyspnoea, HR-QOL and COPD exacerbations. Patients com- pleted the validated Breathlessness Diary, a singleitem dyspnoea measure derived from the BCSS, ${ }^{[23]}$ on a daily basis. The item was scored on a 5-point Likert-type scale, ranging from 0 to 4 , with higher scores indicating more severe dyspnoea. Based on a previous study, ${ }^{[24]}$ a change of $\geq 0.2$ units in dyspnoea score was identified as clinically relevant (i.e. minimal important difference [MID]) and was specified a priori. HR-QOL was evaluated at screening, randomization and the end of months 1,2 and 6 using the St George's Respiratory Questionnaire (SGRQ), ${ }^{[25,26]}$ for which a change of 4 units is considered clinically meaningful. ${ }^{[27]}$ This threshold for a clinically meaningful change was specified $a$ priori, and patients were categorized as experiencing decreases or increases of $\geq 4$ units in the SGRQ total score. COPD exacerbations, defined as worsening of COPD symptoms that required treatment with oral corticosteroids and/or hospitalization, were recorded by patients in their diary cards and confirmed by the study coordinators and/or investigators at the clinic visit.

Secondary symptom variables, including cough and sputum scores, sleep score and rescue medication use, were recorded on a daily basis by patients. Cough and sputum scores were recorded

Table I. Concomitant medications

\begin{tabular}{|c|c|}
\hline Allowed & Disallowed \\
\hline $\begin{array}{l}\text { Ephedrine-free (or other bronchodilator-free) antitussives and } \\
\text { mucolytics }\end{array}$ & $\begin{array}{l}\text { Long-acting anticholinergics } \\
\text { Inhaled LABAs (other than study medication) }\end{array}$ \\
\hline Nasal corticosteroids & Inhaled SABAs (other than salbutamol [albuterol] for rescue) \\
\hline Stable-dose non-nebulized ipratropium bromide ${ }^{a}$ & Oral $\beta_{2}$-adrenoceptor agonists \\
\hline Oral or ophthalmic cardioselective $\beta$-adrenoceptor antagonists ${ }^{b}$ & Ephedrine-containing medication \\
\hline Study-provided salbutamol (albuterol) as rescue medication ${ }^{c}$ & Leukotriene receptor antagonists and 5-lipoxygenase inhibitors \\
\hline $\begin{array}{l}\text { Medications allowed for exacerbations after randomization: } \\
\text { oral and parenteral corticosteroids (not depot formulations) }\end{array}$ & $\begin{array}{l}\text { Xanthine-containing derivatives (except in short-term treatment of } \\
\text { exacerbations) }\end{array}$ \\
\hline acute use of xanthines & Disodium cromoglygates \\
\hline $\begin{array}{l}\text { increased use of inhaled } \beta_{2} \text {-adrenoceptor agonists and } \\
\text { ipratropium bromide }\end{array}$ & $\begin{array}{l}\text { Non-cardioselective } \beta \text {-adrenoceptor antagonists } \\
\text { ICSs (other than study medication) }^{d}\end{array}$ \\
\hline \multicolumn{2}{|l|}{ nebulized $\beta_{2}$-adrenoceptor agonists and ipratropium bromide } \\
\hline \multicolumn{2}{|l|}{ a A } \\
\hline \multicolumn{2}{|l|}{ evidence of bronchospasm. } \\
\hline \multicolumn{2}{|l|}{ c Not to be used within 6 hours of each clinic visit. } \\
\hline \multicolumn{2}{|c|}{ d Allowed during the run-in period. } \\
\hline \multicolumn{2}{|c|}{ ICSs = inhaled corticosteroids; LABA = long-acting $\beta_{2}$-adrenoceptor agonist; SABA = short-acting $\beta_{2}$-adrenoceptor agonist. } \\
\hline
\end{tabular}


before the evening dose of study medication, and each were assessed on a scale from 0 to 4 , with higher scores indicating an increased number of symptoms or more severe symptoms. The BCSS is the sum total of the individual dyspnoea, cough and sputum scores, and the total scores range from 0 to $12 .^{[23]}$ Sleep score was recorded before the morning dose of study medication and assessed on a scale from 0 to 4, with higher scores indicating more sleep disturbances (based on the number and/or duration of night-time awakenings, including early awakenings, caused by COPD symptoms [e.g. dyspnoea, cough and chest tightness]). Rescue medication use (inhalations/day) was recorded in the morning and evening before administration of study medication. The percentages of awakening-free nights (defined as nights for which the patient reported a sleep score of 0 ) and rescue medication-free days (defined as days for which the patient reported no daytime or night-time rescue medication use) were calculated.

\section{Safety Evaluations}

The incidence of adverse events (AEs), serious AEs (SAEs) and discontinuations due to AEs (DAEs) was assessed. AEs were recorded by the patient on a diary card throughout the study. AEs also were collected at the beginning of each clinic visit and during the final follow-up telephone call. Symptoms or signs consistent with COPD (e.g. bronchitis, cough, phlegm, increased sputum, dyspnoea, wheeze) were to be reported as AEs only if they were serious, new to the patient, inconsistent with the patient's pre-existing COPD history within 1 year of the screening visit or when they resulted in discontinuation from the study. Investigators assessed the causal relationship of AEs to study medication.

AEs representing typical class effects associated with exposure to corticosteroids (e.g. local, systemic) or $\beta_{2}$-adrenoceptor agonists (e.g. cardiac effects, tremor, anxiety) were described. AEs of oral candidiasis were based on history/physical examination and did not require confirmatory culture. Other AEs of interest included those related to pneumonia and other respiratory tract infections.
In all patients, blood and urine samples were collected, and comprehensive physical examinations were carried out at the time of screening and at the end of month 6 or the last visit. Blood samples were analysed by a central laboratory (Quest Diagnostics Clinical Laboratories, Van Nuys, CA, USA). Vital signs, including heart rate and blood pressure, were measured at all clinic visits. 12-Lead ECGs were performed in all patients before and 30-60 minutes after inhalation of study drug at randomization and at the end of months 2 and 6 . ECG results were evaluated by a cardiologist in a blinded fashion through an independent ECG service provider (eResearch Technology, Inc., Philadelphia, PA, USA). Clinically important abnormalities and shifts were identified as follows: heart rate $>100$ beats per minute (bpm) or a change of $\geq 20 \mathrm{bpm}$ from baseline; QT/QTc interval $\geq 500 \mathrm{msec}$ or an increase of $>60 \mathrm{msec}$ from baseline. Samples to assess 24-hour urinary cortisol levels were collected in a subset of patients $(n=437)$ at or before randomization and within 1 week before the 6month visit.

\section{Statistical Analyses}

The efficacy analysis set (i.e. intention-to-treat population) included all randomized patients who received at least one dose of study medication and contributed sufficient data for at least one co-primary or secondary efficacy endpoint during the randomized treatment period. The safety analysis population included randomized patients who had received at least one dose of study medication and from whom any post-randomization data were available. For the subsets of patients who underwent serial spirometry and 24-hour urinary cortisol measurement, analysis sets were defined as randomized, treated patients who had baseline and on-treatment values for the variable being assessed.

A sample size of 190 evaluable patients per treatment group was estimated to provide $\geq 90 \%$ power to detect a difference of $0.1 \mathrm{~L}$ (assuming a standard deviation of $0.3 \mathrm{~L}$ ) in the change from baseline in pre-dose $\mathrm{FEV}_{1}$ between treatment groups. The sample size also provided $80-90 \%$ power to detect dif- 
ferences in dyspnoea scores and SGRQ total score. All hypothesis testing was conducted using 2-sided tests; $\mathrm{p} \leq 0.05$ was considered statistically significant.

The prespecified primary comparators for the coprimary efficacy variables were (i) formoterol DPI for pre-dose $\mathrm{FEV}_{1}$ to demonstrate the contribution of budesonide to the anti-inflammatory action of budesonide/formoterol pMDI; and (ii) budesonide pMDI for 1-hour post-dose $\mathrm{FEV}_{1}$ to demonstrate the contribution of formoterol to the bronchodilator action of budesonide/formoterol pMDI. Analyses of the primary and key secondary efficacy endpoints were adjusted for multiplicity using a sequential approach to hypothesis testing at the 5\% significance level. No formal hypothesis testing of the safety data was performed, although treatment differences for certain variables are described with confidence intervals and p-values (used as flagging devices).

Changes from baseline in the co-primary efficacy variables were analysed using an analysis of covariance (ANCOVA) model, adjusting for treatment, country and baseline. Changes from baseline in other secondary efficacy variables were analysed using methodology similar to that described for the co-primary efficacy variables. A Cochrane-MantelHaenszel test, adjusted for country and prespecified in the statistical analysis plan, was used to separately evaluate the percentages of patients with increases and decreases that met the MID for SGRQ total score. The number of exacerbations per patienttreatment year was compared between treatment groups using a Poisson regression model, adjusting for country, differential time from randomization and over dispersion. In addition, a sensitivity analysis, including a region-by-treatment interaction term, was added to the model for the co-primary variables to test for treatment differences by region.

Geometric mean 24-hour urinary cortisol levels at the end of treatment were compared between treatment groups using a multiplicative ANCOVA model. Mean changes from baseline in ECG variables were compared between treatment groups using methodology similar to that described for the co- primary efficacy variables. AE variables were summarized descriptively.

\section{Results}

\section{Patients}

Patient disposition is shown in figure 2. Discontinuation rates were significantly lower in the budesonide/formoterol 160/9 $\mu \mathrm{g}$ and 320/9 $\mu \mathrm{g}$ groups compared with the placebo, budesonide and formoterol groups ( $\mathrm{p} \leq 0.018)$. Discontinuation rates were not significantly different for either of the monocomponents compared with placebo. The overall discontinuation rate was higher in the US $(28.6 \%)$ than in non-US countries $(12.2 \%)$.

Demographic and baseline disease characteristics were generally similar across treatment groups (table II). Approximately half of the patients were $\geq 65$ years of age and approximately $12 \%$ were $\geq 75$ years of age. Most patients had severe $(58.2 \%)$ or very severe (22\%) COPD, while $19.3 \%$ had moderate and $0.3 \%$ had mild COPD, based on postbronchodilator $\mathrm{FEV}_{1}$ at screening and 2007 Global Initiative for Chronic Obstructive Lung Disease criteria $\left(0.2 \%\right.$ had missing data). ${ }^{[1]}$ The mean prebronchodilator $\mathrm{FEV}_{1}$ at screening was approximately $34 \%$ of predicted normal. Approximately $40-45 \%$ of participants were current smokers with a median smoking history of 40 pack-years. Co-morbid conditions affecting the overall population included hypertension (42\%), lipid profile abnormalities $(24 \%)$, cardiac disease (18\%), diabetes mellitus $(10 \%)$, osteoporosis $(8 \%)$ and cataracts (5\%). Demographic and baseline disease characteristics were generally similar across regions, with the exception that higher percentages of females and Black patients were reported in US $(41.5 \%$ and $8.2 \%$, respectively) versus non-US regions $(24.8 \%$ and $0.5 \%$, respectively).

\section{Efficacy Evaluations}

\section{Co-Primary Efficacy Variables}

Improvements in pre-dose $\mathrm{FEV}_{1}$ were significantly greater in patients who were treated with 


\begin{tabular}{|l|l|}
\hline \begin{tabular}{|l|} 
Screened \\
$(\mathrm{N}=2381)$
\end{tabular} & $\begin{array}{l}\text { Not randomized }(\mathrm{n}=677) \\
\text { - Eligibility criteria not fulfilled }(\mathrm{n}=439) \\
\text { - Withdrew consent }(\mathrm{n}=129) \\
\text { - AE }(\mathrm{n}=46) \\
\text { - Other }(\mathrm{n}=42) \\
\text { - Lost to follow-up }(\mathrm{n}=20) \\
\text { - Unknown }(\mathrm{n}=1)\end{array}$ \\
\hline \begin{tabular}{|l} 
Randomized \\
$(\mathrm{N}=1704)^{1}$
\end{tabular} &
\end{tabular}

\begin{tabular}{|c|c|c|c|c|c|c|}
\hline & I & I & & & & \\
\hline $\begin{array}{c}\text { BUD/FM pMDI } \\
320 / 9 \mu \mathrm{g} \\
(\mathrm{n}=277)\end{array}$ & $\begin{array}{c}\text { BUD/FM pMDI } \\
160 / 9 \mu \mathrm{g} \\
(\mathrm{n}=281)\end{array}$ & $\begin{array}{c}\text { BUD pMDI } 320 \mu \mathrm{g} \\
+ \text { FM DPI } 9 \mu \mathrm{g} \\
(\mathrm{n}=287)\end{array}$ & $\begin{array}{l}\text { BUD pMDI } \\
320 \mu \mathrm{g} \\
(\mathrm{n}=275)\end{array}$ & $\begin{array}{c}\text { FM DPI } \\
9 \mu \mathrm{g} \\
(\mathrm{n}=284)\end{array}$ & $\begin{array}{c}\mathrm{PL} \\
(\mathrm{n}=300)\end{array}$ & TOTAL \\
\hline $\begin{array}{l}\text { Took } \\
\text { study med } \\
(\mathrm{n}=277)\end{array}$ & $\begin{array}{l}\text { Took } \\
\text { study med } \\
(\mathrm{n}=281)\end{array}$ & $\begin{array}{l}\text { Took } \\
\text { study med } \\
(\mathrm{n}=287)\end{array}$ & $\begin{array}{l}\text { Took } \\
\text { study med } \\
(\mathrm{n}=275)\end{array}$ & $\begin{array}{l}\text { Took } \\
\text { study med } \\
(\mathrm{n}=284)\end{array}$ & $\begin{array}{c}\text { Took } \\
\text { study med } \\
(\mathrm{n}=300)\end{array}$ & $\begin{array}{c}\text { Took } \\
\text { study med } \\
\text { ( } n=1704)\end{array}$ \\
\hline $\begin{array}{l}\text { Discontinued } \\
(\mathrm{n}=39 ; 14.1 \%) \\
\text { Eligibility } \\
\text { criteria not } \\
\text { fulfilled } \\
(\mathrm{n}=3) \\
\text { - AE }(\mathrm{n}=21) \\
\text { - Withdrew } \\
\text { consent } \\
(\mathrm{n}=6) \\
\text { - Lost to } \\
\text { follow-up } \\
(\mathrm{n}=4) \\
\text { - Other }(n=5)\end{array}$ & $\begin{array}{l}\text { Discontinued } \\
(n=38 ; 13.5 \%) \\
\text { Eligibility } \\
\text { criteria not } \\
\text { fulfilled } \\
(n=1) \\
\text { AE }(n=20) \\
\text { Withdrew } \\
\text { consent } \\
(n=8) \\
\text { Lost to } \\
\text { follow-up } \\
(n=3) \\
\bullet \text { Other }(n=6)\end{array}$ & $\begin{array}{l}\text { Discontinued } \\
(n=48 ; 16.7 \%) \\
\bullet \text { Eligibility } \\
\text { criteria not } \\
\text { fulfilled } \\
(n=4) \\
\bullet \text { AE }(n=14) \\
\cdot \text { Withdrew } \\
\text { consent } \\
(n=14) \\
\cdot \text { Lost to } \\
\text { follow-up } \\
(n=6) \\
\cdot \text { Other }(n=10)\end{array}$ & $\begin{array}{l}\text { Discontinued } \\
(\mathrm{n}=\mathbf{6 3} ; \mathbf{2 2 . 9 \%}) \\
\text { Eligibility } \\
\text { criteria not } \\
\text { fulfilled } \\
(\mathrm{n}=2) \\
\text { AE }(\mathrm{n}=26) \\
\text { - Withdrew } \\
\text { consent } \\
(\mathrm{n}=20) \\
\text { Lost to } \\
\text { follow-up } \\
(\mathrm{n}=4) \\
\text { Other }(n=10) \\
\text { Missing }(n=1)\end{array}$ & $\begin{array}{l}\text { Discontinued } \\
(n=61 ; 21.5 \%) \\
\bullet \text { Eligibility } \\
\text { criteria not } \\
\text { fulfilled } \\
(n=4) \\
\cdot \text { AE }(n=34) \\
\text { Withdrew } \\
\text { consent } \\
(n=12) \\
\cdot \text { Lost to } \\
\text { follow-up } \\
(n=1) \\
\cdot \text { Other }(n=10)\end{array}$ & $\begin{array}{l}\text { Discontinued } \\
(n=77 ; 25.7 \%) \\
\text { Eligibility } \\
\text { criteria not } \\
\text { fulfilled } \\
(n=3) \\
\bullet \text { AE }(n=28) \\
\text {. Withdrew } \\
\text { consent } \\
(n=27) \\
\bullet \text { Lost to } \\
\text { follow-up } \\
(n=7) \\
\bullet \text { Other }(n=12)\end{array}$ & $\begin{array}{l}\text { Discontinued } \\
(\mathrm{n}=\mathbf{3 2 6} ; \mathbf{1 9 . 1} \%) \\
\text { Eligibility } \\
\text { criteria not } \\
\text { fulfilled } \\
(\mathrm{n}=17) \\
\text { AE }(\mathrm{n}=143) \\
\text { - Withdrew } \\
\text { consent } \\
(\mathrm{n}=87) \\
\cdot \text { Lost to } \\
\text { follow-up } \\
(\mathrm{n}=25) \\
\text { Other }(n=53) \\
\text { - Missing }(n=1)\end{array}$ \\
\hline $\begin{array}{l}\text { Completed } \\
\text { study } \\
(n=238)\end{array}$ & $\begin{array}{c}\text { Completed } \\
\text { study } \\
(n=243)\end{array}$ & $\begin{array}{l}\text { Completed } \\
\text { study } \\
(n=239)\end{array}$ & $\begin{array}{l}\text { Completed } \\
\text { study } \\
(n=212)\end{array}$ & $\begin{array}{l}\text { Completed } \\
\text { study } \\
(n=223)\end{array}$ & $\begin{array}{l}\text { Completed } \\
\text { study } \\
(n=223)\end{array}$ & $\begin{array}{l}\text { Completed } \\
\text { study } \\
(n=1378)\end{array}$ \\
\hline
\end{tabular}

Fig. 2. Patient disposition. 1 The efficacy analysis set included 1697 patients. Seven patients were excluded because of an early study site closure; data from these patients were included in the safety analysis set. AE = adverse event; $\mathbf{B U D}=$ budesonide; DPI = dry powder inhaler; $\mathbf{F M}=$ formoterol; $\mathbf{m e d}=$ medication; $\mathbf{P L}=$ placebo; $\mathbf{p M D I}=$ pressurized metered-dose inhaler.

budesonide/formoterol 320/9 $\mu \mathrm{g}$ compared with formoterol (primary comparison), budesonide and placebo ( $\mathrm{p} \leq 0.026$; table III). Budesonide/formoterol $160 / 9 \mu \mathrm{g}$ demonstrated significantly greater improvements in pre-dose $\mathrm{FEV}_{1}$ compared with budesonide and placebo ( $\mathrm{p} \leq 0.002)$, but not compared with formoterol (the pre-specified primary comparator). Treatment with formoterol also resulted in significantly greater improvements in pre-dose $\mathrm{FEV}_{1}$ compared with placebo $(\mathrm{p}=0.037)$. Patients treated with budesonide did not experience significant improvements in pre-dose $\mathrm{FEV}_{1}$ compared with placebo. Improvements in pre-dose $\mathrm{FEV}_{1}$ were apparent at the first assessment after randomization (month 1) following treatment with both budesonide/formoterol dosage strengths and were generally maintained over the 6-month treatment period with budesonide/formoterol 320/9 $\mu \mathrm{g}$ (figure 3a).

Improvements in 1-hour post-dose $\mathrm{FEV}_{1}$ were significantly greater in the budesonide/formoterol 320/9 $\mu \mathrm{g}$ group compared with the budesonide ( $\mathrm{p}<0.001$; primary comparison), formoterol $(\mathrm{p}=0.039)$ and placebo $(\mathrm{p}<0.001)$ groups $($ table III). Treatment with budesonide/formoterol 160/ $9 \mu \mathrm{g}$ resulted in significantly greater improvements in 1-hour post-dose $\mathrm{FEV}_{1}$ compared with budeso- 


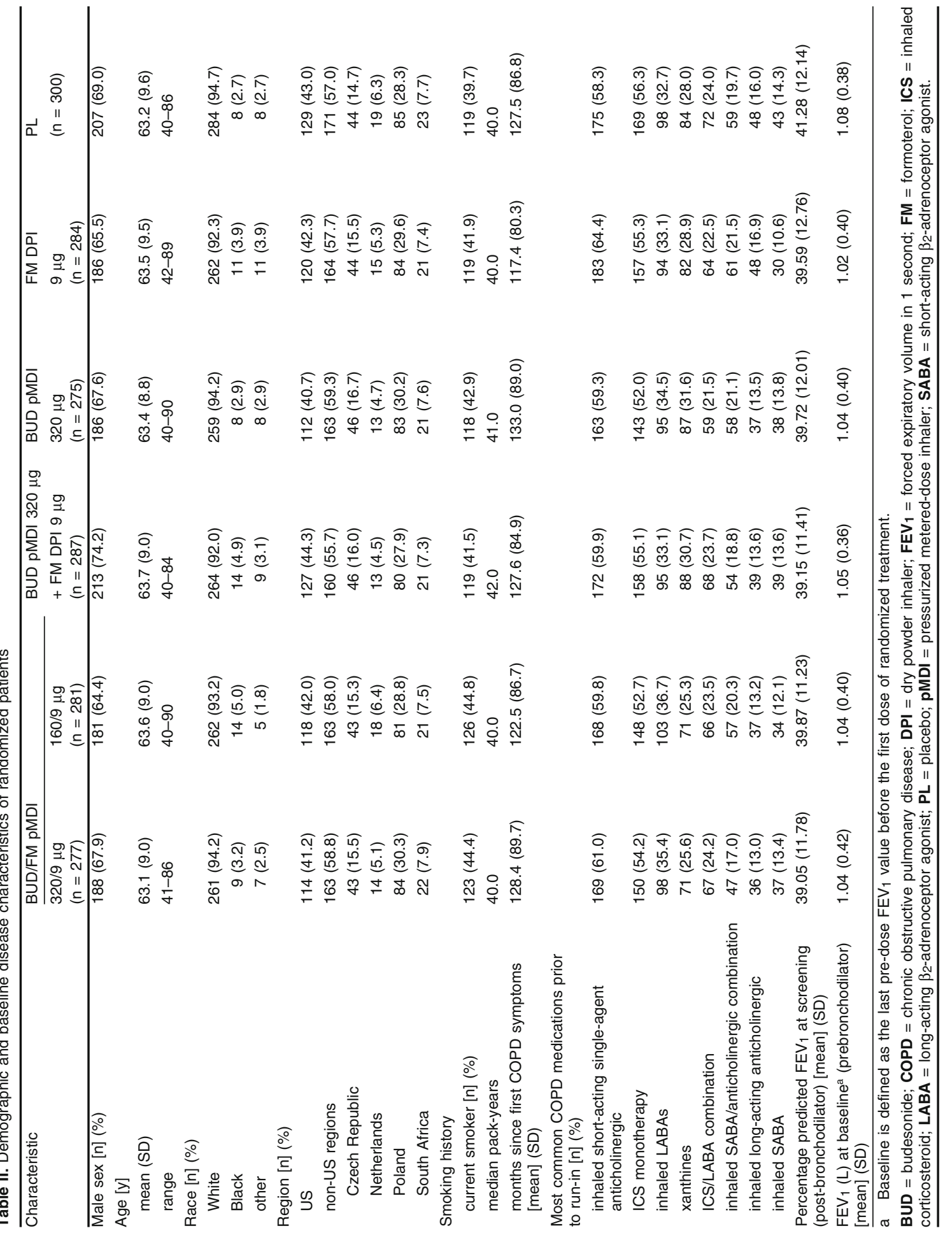




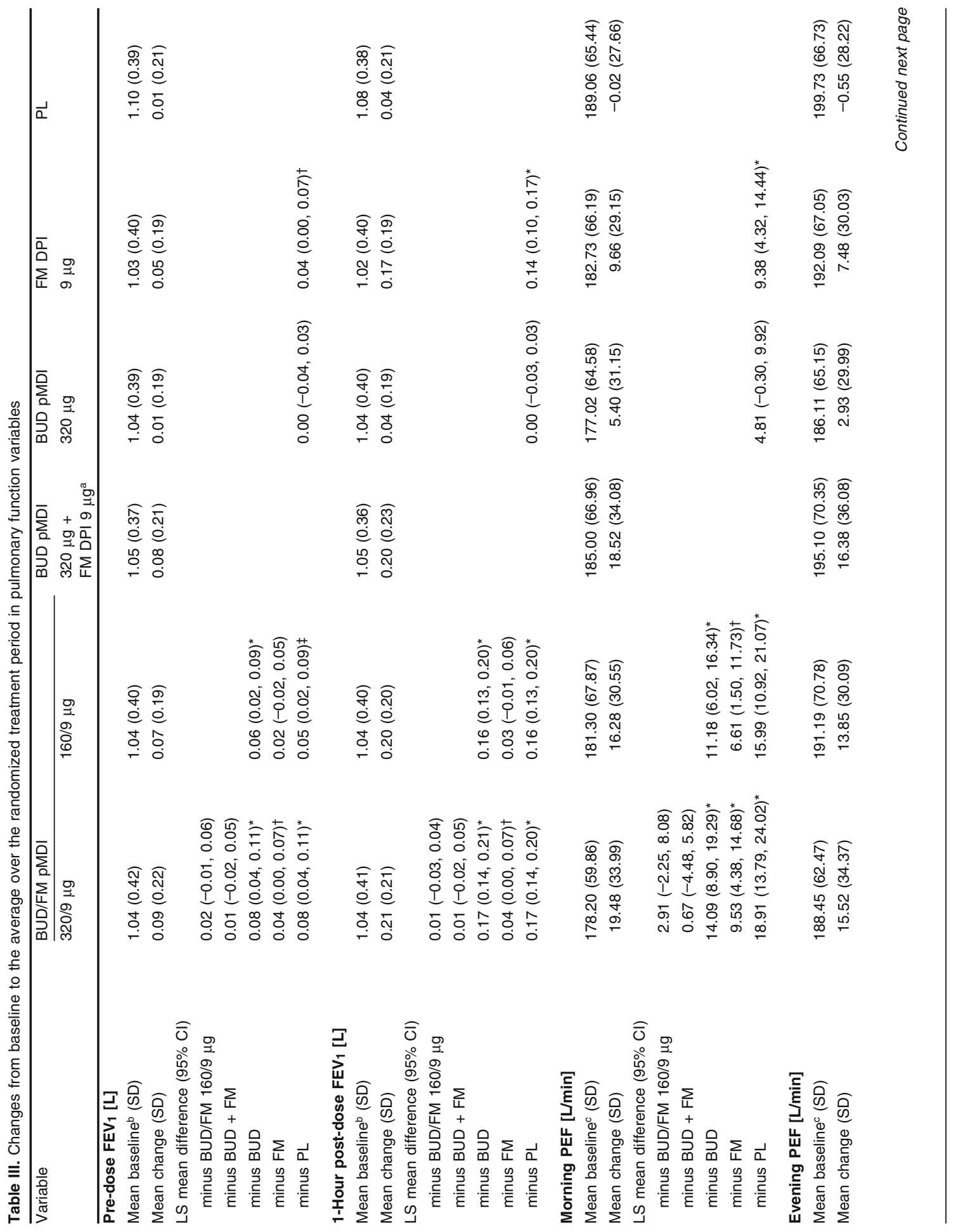




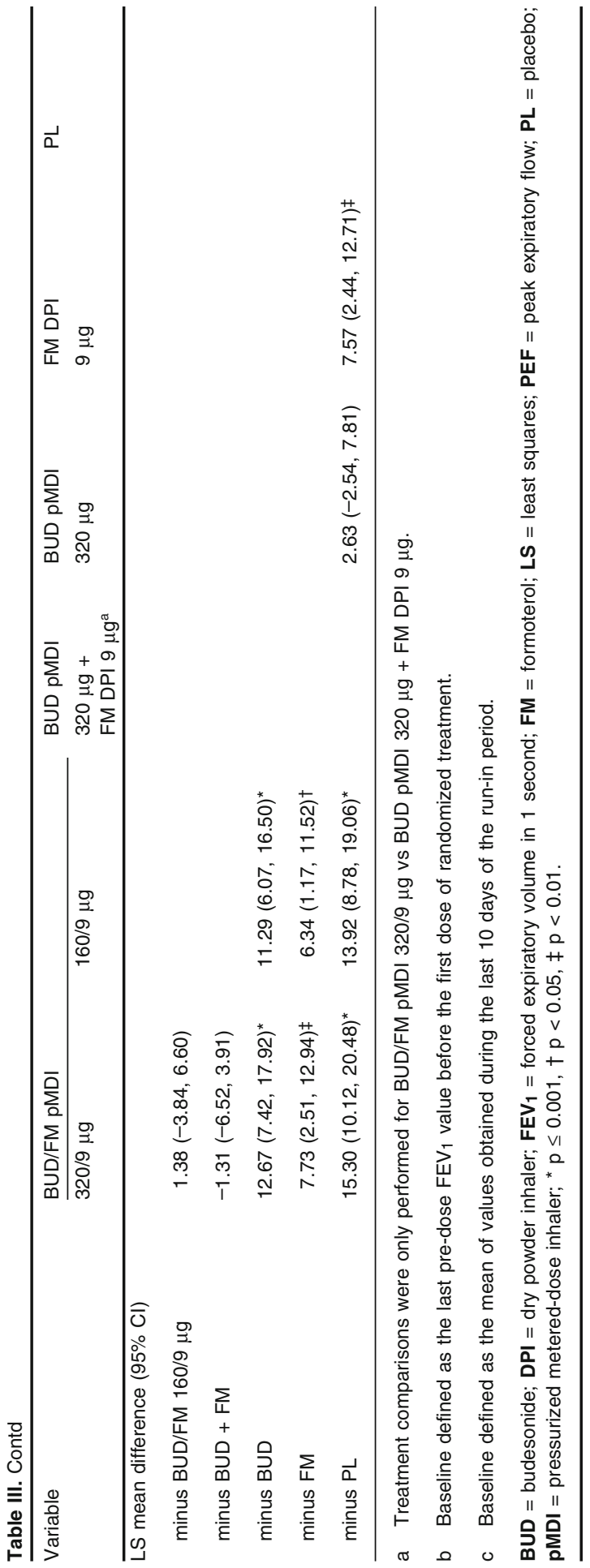

nide and placebo $(\mathrm{p}<0.001)$. Formoterol also resulted in significantly greater improvements in 1-hour post-dose $\mathrm{FEV}_{1}$ compared with placebo $(\mathrm{p}<0.001$; table III). Improvements were apparent on the day of randomization and were maintained over the 6-month treatment period after treatment with both budesonide/formoterol dosage strengths and formoterol (figure $3 b$ ).

The results of the region-by-treatment interaction sensitivity analyses for the co-primary efficacy variables were not significant for either variable ( $\mathrm{p} \geq 0.148)$.

\section{Secondary Pulmonary Function Variables}

Both budesonide/formoterol dosage strengths resulted in significantly greater mean improvements in baseline-adjusted average 12-hour FEV 1 compared with budesonide and placebo at randomization and end of treatment ( $\mathrm{p} \leq 0.012$, all comparisons); budesonide/formoterol 320/9 $\mu \mathrm{g}$ demonstrated significantly greater improvements compared with formoterol at end of treatment $(\mathrm{p}=0.030)$. Patients receiving budesonide/formoterol combination therapy or formoterol alone experienced a mean improvement in $\mathrm{FEV}_{1}$ of approximately $15-18 \%$ at 5 minutes after dose administration at the randomization visit (figure $4 a$ ) and end of treatment (figure 4b); an improvement in $\mathrm{FEV}_{1}$ of $\geq 15 \%$ is generally considered clinically significant. At the 12-hour timepoint, significant improvements in $\mathrm{FEV}_{1}$ were observed at randomization for both budesonide/formoterol dosage strengths compared with budesonide and placebo ( $\mathrm{p} \leq 0.006)$ and for formoterol compared with placebo $(\mathrm{p}<0.001)$; this effect was maintained at end of treatment for budesonide/formoterol 320/9 $\mu \mathrm{g}$ ( $\mathrm{p} \leq 0.019$ vs budesonide, formoterol and placebo). Significantly greater adjusted mean improvements from baseline in maximum $\mathrm{FEV}_{1}$ during 12-hour serial spirometry were observed on the day of randomization for budesonide/ formoterol 320/9 $\mu \mathrm{g}(0.32 \mathrm{~L})$ and $160 / 9 \mu \mathrm{g}(0.30 \mathrm{~L})$ compared with budesonide $(0.15 \mathrm{~L})$ and placebo $(0.16 \mathrm{~L})$, and for formoterol $(0.28 \mathrm{~L})$ compared with placebo $(0.16 \mathrm{~L})$ [p $<0.001$ for all comparisons]. At the end of treatment, adjusted mean improvements in maximum $\mathrm{FEV}_{1}$ were significantly greater with 
- BUD/FM pMDI 320/9 $\mu \mathrm{g}$

- BUD/FM pMDI 160/9 $\mu \mathrm{g}$

- BUD pMDI $320 \mu \mathrm{g}$ + FM DPI $9 \mu \mathrm{g}$

- BUD pMDI $320 \mu \mathrm{g}$

$\times$ FM DPI $9 \mu \mathrm{g}$

$+\mathrm{PL}$

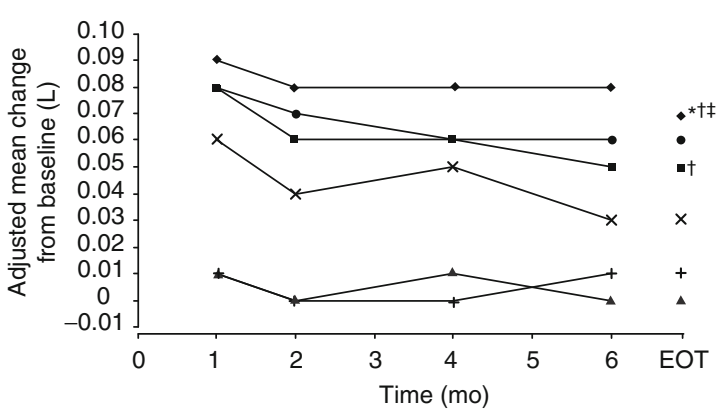

b

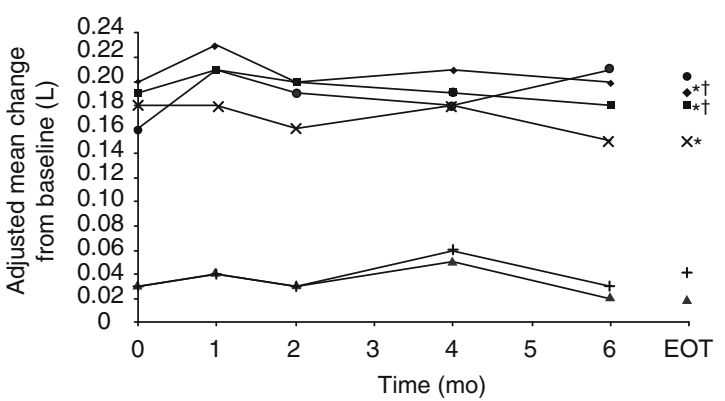

Fig. 3. Adjusted mean change from baseline in (a) pre-dose forced expiratory volume in 1 second $\left(\mathrm{FEV}_{1}\right)$ and (b) 1 -hour post-dose $\mathrm{FEV}_{1}$ by study visit over the randomized treatment period and end of treatment $(\mathrm{EOT})$. BUD = budesonide; $\mathbf{D P I}=$ dry powder inhaler; $\mathbf{F M}=$ formoterol $\mathbf{P L}=$ placebo; $\mathbf{p M D I}=$ pressurized metered-dose inhaler. ${ }^{*} p<0.01$ vs PL; $\dagger p<0.05$ vs BUD pMDI; $\ddagger p<0.05$ vs FM DPI.

budesonide/formoterol 320/9 $\mu \mathrm{g}(0.27 \mathrm{~L})$ compared with placebo $(0.14 \mathrm{~L})$ [p $=0.003]$ and for budesonide/formoterol $320 / 9 \mu \mathrm{g}(0.27 \mathrm{~L})$ and $160 / 9 \mu \mathrm{g}$ $(0.21$ L) compared with budesonide $(0.11$ L) [ $\leq$ 0.014]. In patients undergoing serial spirometry, adjusted mean improvements in 1-hour postdose IC values over the treatment period were significantly greater after treatment with budesonide/ formoterol 320/9 $\mu \mathrm{g}(0.29 \mathrm{~L})$ and $160 / 9 \mu \mathrm{g}(0.29 \mathrm{~L})$ compared with budesonide $(0.08 \mathrm{~L})$ and placebo $(0.10 \mathrm{~L}$; all comparisons $\mathrm{p}<0.001)$, and with formoterol $(0.34 \mathrm{~L})$ compared with placebo $(\mathrm{p}<0.001)$. Changes in pre-dose IC were not significantly dif- ferent between the treatment groups. Improvements in morning and evening PEF were significantly greater for both budesonide/formoterol dosage strengths compared with budesonide, formoterol and placebo $(\mathrm{p} \leq 0.016)$ and for formoterol compared with placebo ( $\mathrm{p} \leq 0.004$; table III).

\section{Secondary Efficacy Variables}

Patients treated with both budesonide/formoterol dosage strengths experienced significantly greater improvements in dyspnoea scores compared with budesonide, formoterol and placebo $(\mathrm{p} \leq 0.044$; table IV). Improvements in dyspnoea were clinically meaningful (i.e. reduction of $\geq 0.2$ units [MID]) for all active treatment groups compared with their baseline values, although neither budesonide/formo-
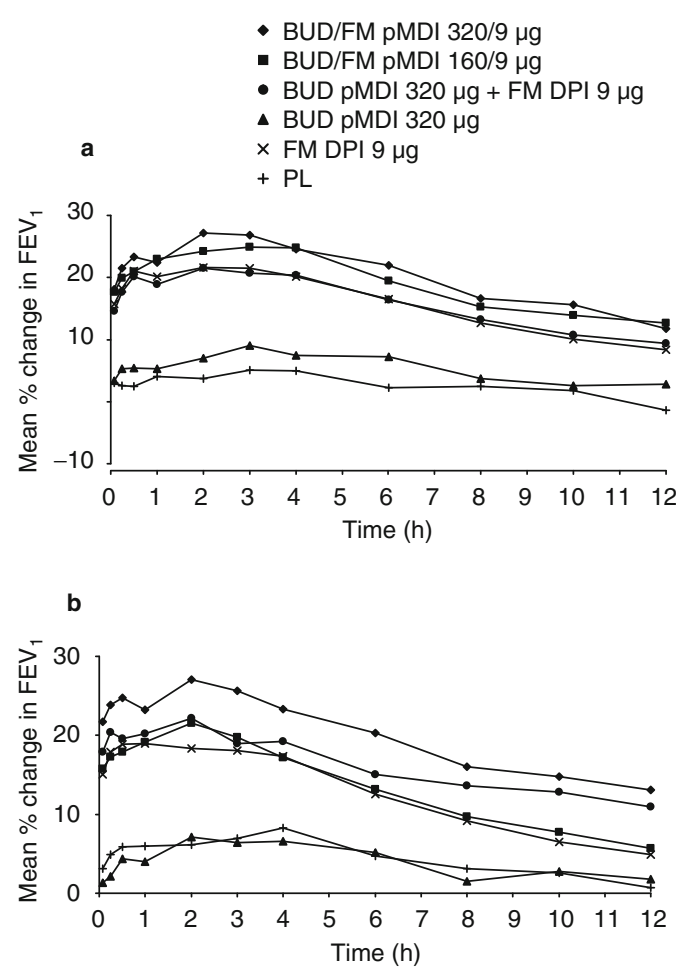

Fig. 4. Mean percentage change from baseline (defined as the predose $F E V_{1}$ value before the first dose of randomized treatment) in forced expiratory volume in 1 second $\left(\mathrm{FEV}_{1}\right)$ over 12 hours at (a) randomization and (b) end of treatment (EOT). The first time point for assessment occurred 5 minutes after administration of study medication on the day of randomization and EOT. BUD = budesonide; $\mathbf{D P I}=$ dry powder inhaler; $\mathbf{F M}=$ formoterol; $\mathrm{PL}$ = placebo; $\mathbf{p M D I}=$ pressurized metered-dose inhaler. 
terol dosage strength reached the prespecified MID compared with placebo (based on comparison of least squares mean changes from baseline).

Both budesonide/formoterol dosage strengths resulted in significant improvements in the COPDrelated symptoms of breathlessness, cough and sputum (summed as the BCSS), and in sleep score and percentage of awakening-free nights compared with placebo ( $\mathrm{p} \leq 0.029$; table IV). Daily rescue medication use was significantly decreased and rescue medication-free days were significantly increased with both budesonide/formoterol dosage strengths compared with budesonide and placebo $(\mathrm{p}<0.001)$, and with formoterol compared with placebo $(\mathrm{p} \leq 0.002)$.

Improvements in the SGRQ total scores were significantly greater $(\mathrm{p} \leq 0.035)$ in both budesonide/ formoterol groups compared with the budesonide, formoterol and placebo groups (table V). These improvements were clinically meaningful (i.e. reduction from baseline of $\geq 4$ points) for both budesonide/formoterol dosage strengths compared with their baseline values at all timepoints assessed (figure 5). However, differences between the active treatment and placebo groups in SGRQ total score did not reach the MID at the end of the treatment period (based on comparison of least squares mean changes from baseline). A significantly $(\mathrm{p} \leq 0.018)$ greater percentage of patients in the budesonide/ formoterol 320/9 $\mu \mathrm{g}(45.5 \%)$ and budesonide/formoterol 160/9 $\mu \mathrm{g}(45.4 \%)$ groups demonstrated a clinically meaningful decrease (i.e. improvement) from baseline to end of treatment in SGRQ total score compared with patients in the placebo group (35.0\%). Conversely, the percentage of patients with increases (i.e. worsening) in SGRQ total score from baseline to end of treatment was significantly ( $\mathrm{p} \leq 0.047$ ) lower in the budesonide/formoterol 320/ $9 \mu \mathrm{g}(22.5 \%)$ and budesonide/formoterol 160/9 $\mu \mathrm{g}$ (23.3\%) groups compared with the placebo $(31.1 \%)$ group.

While this study was not powered to show a difference in exacerbations, the number of COPD exacerbations (requiring oral corticosteroids and/or hospitalization) per patient-treatment year was nu- merically lower (approximately 20-25\%), although not significantly different ( $\mathrm{p} \geq 0.060$ ), in the budesonide-containing groups (budesonide/formoterol 320/9 $\mu \mathrm{g}$ [0.884], budesonide/formoterol 160/9 $\mu \mathrm{g}$ [0.851], budesonide plus formoterol [0.710] and budesonide [0.882]) compared with the formoterol (1.098) and placebo (1.110) groups. This result was driven by the category of COPD exacerbations requiring treatment with oral corticosteroids: budesonide/formoterol 320/9 $\mu \mathrm{g}$ (0.824), budesonide/formoterol $160 / 9 \mu \mathrm{g}(0.826)$, budesonide plus formoterol (0.684), budesonide (0.828), formoterol (1.104) and placebo (1.068); differences were significant for budesonide/formoterol (both dosage strengths) compared with formoterol ( $\mathrm{p} \leq 0.043)$. The total number of COPD exacerbations requiring hospitalization was very low in all treatment groups (range 11-22); the number of events per patienttreatment year was significantly different for budesonide/formoterol 320/9 $\mu \mathrm{g}$ (0.158) compared with other treatment groups $(0.081-0.108)$ except budesonide/formoterol 160/9 $\mu \mathrm{g}$ (0.139), and for budesonide/formoterol 160/9 $\mu \mathrm{g}$ compared with formoterol $(0.081)(\mathrm{p} \leq 0.05)$.

\section{Safety Evaluations}

The mean duration of exposure to randomized treatment was lowest in the placebo group (150.0 days) compared with the budesonide/formoterol 320/9 $\mu \mathrm{g}$ (166.5 days), budesonide/formoterol 160/ $9 \mu \mathrm{g}$ (168.3 days) and budesonide plus formoterol (164.6 days) groups. Both budesonide/formoterol dosage strengths were well tolerated relative to budesonide, formoterol and placebo. The percentage of patients with at least one AE was generally similar across treatment groups: budesonide/formoterol $320 / 9 \mu \mathrm{g}$ (57.4\%), budesonide/formoterol 160/9 $\mu \mathrm{g}$ $(52.3 \%)$, budesonide plus formoterol (49.5\%), budesonide $(57.5 \%)$, formoterol $(56.7 \%)$ and placebo $(50.7 \%)$. Overall, the majority of AEs were of mild $(51.4 \%)$ or moderate $(36.1 \%)$ intensity, with a similar distribution of intensities observed across treatment groups.

The most commonly reported AEs (by $\geq 3 \%$ of randomized patients) were COPD, nasopharyngitis, 


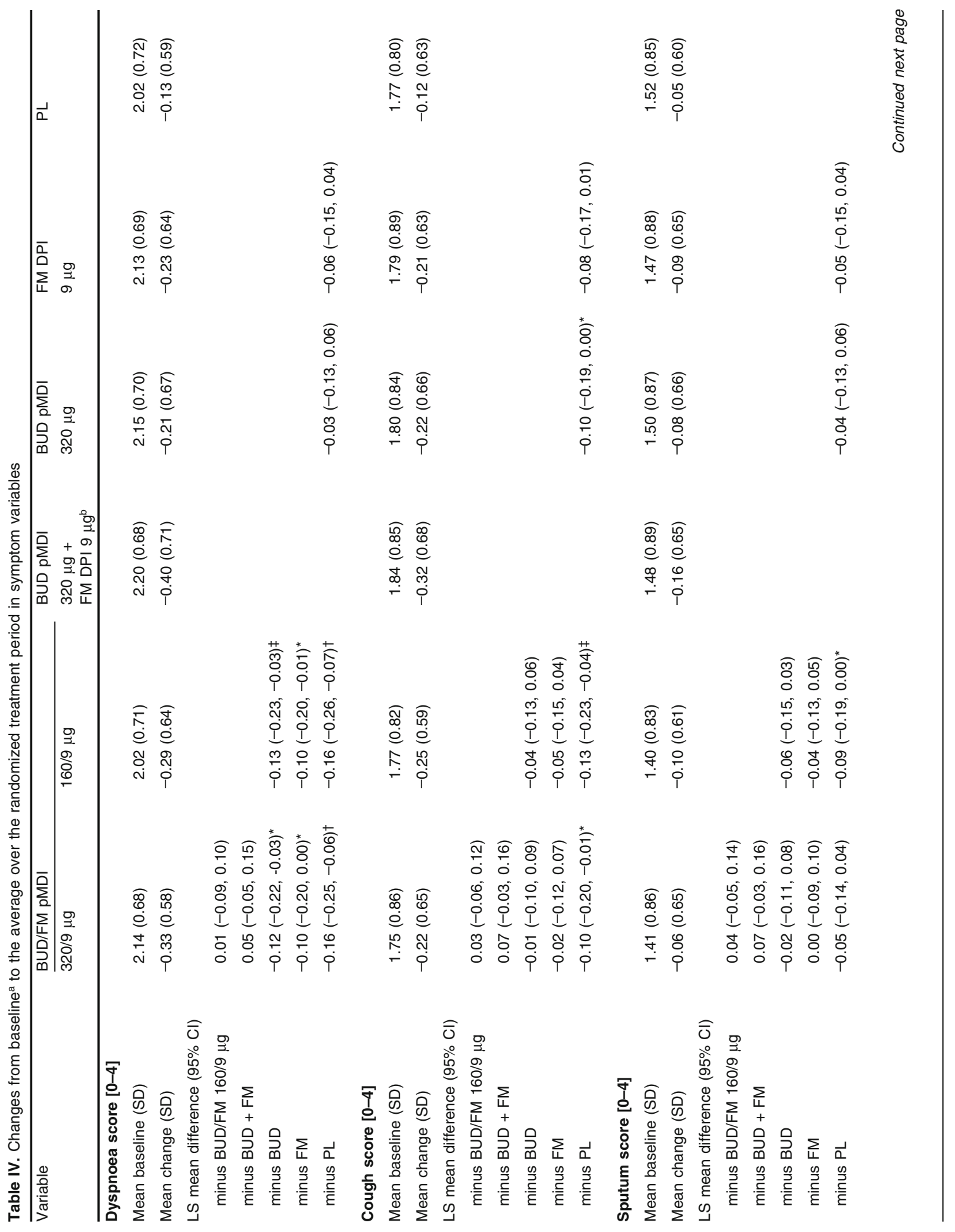




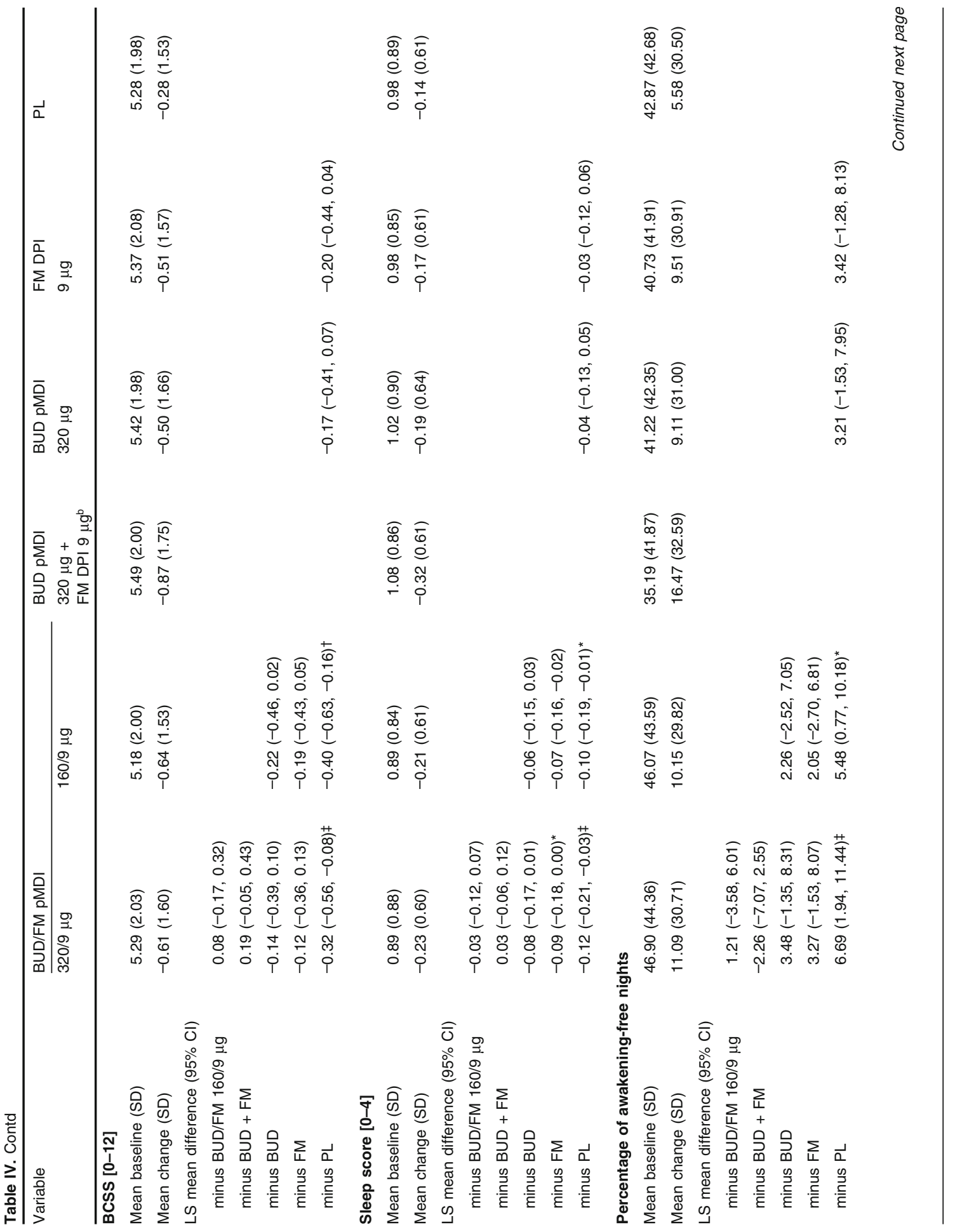




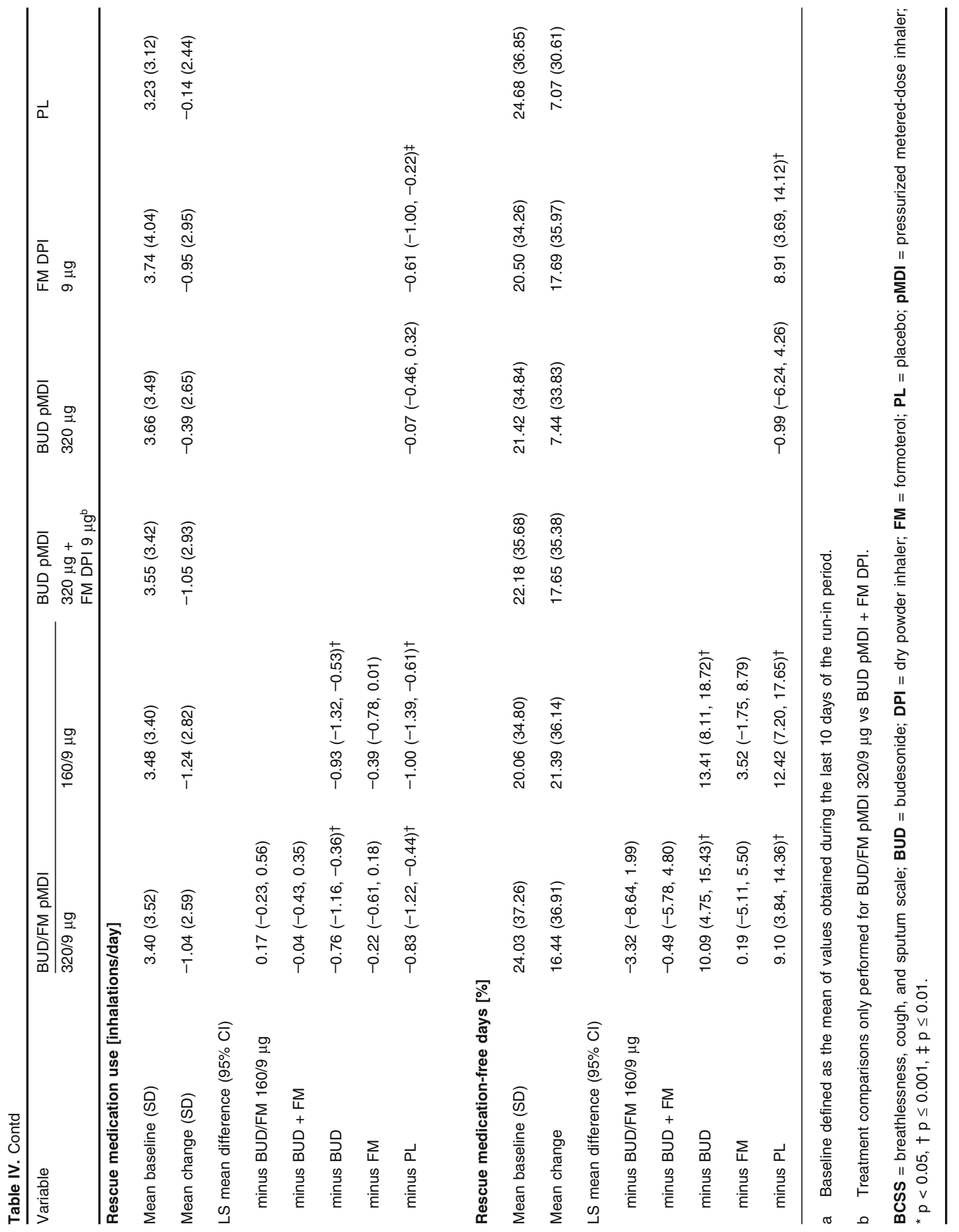




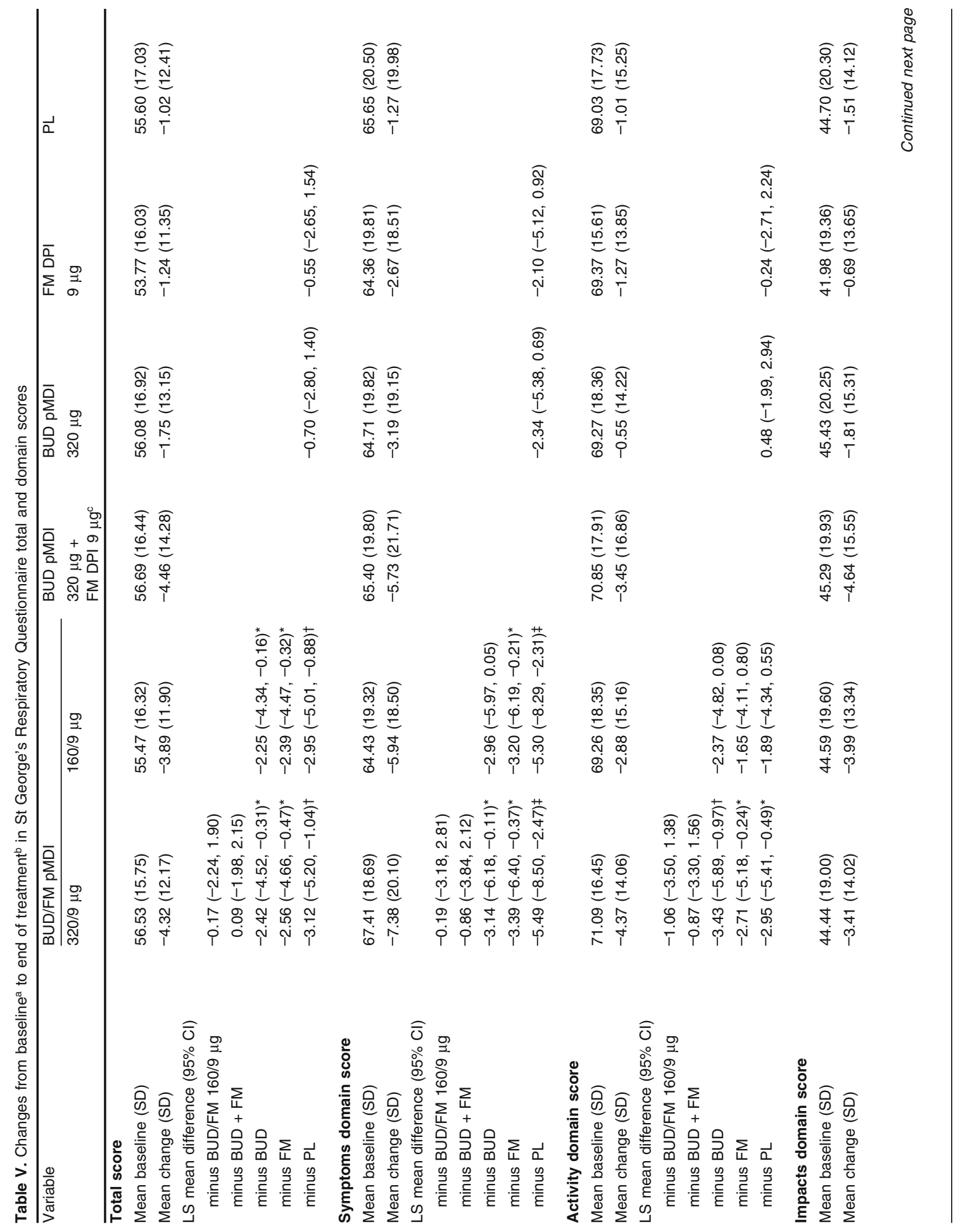




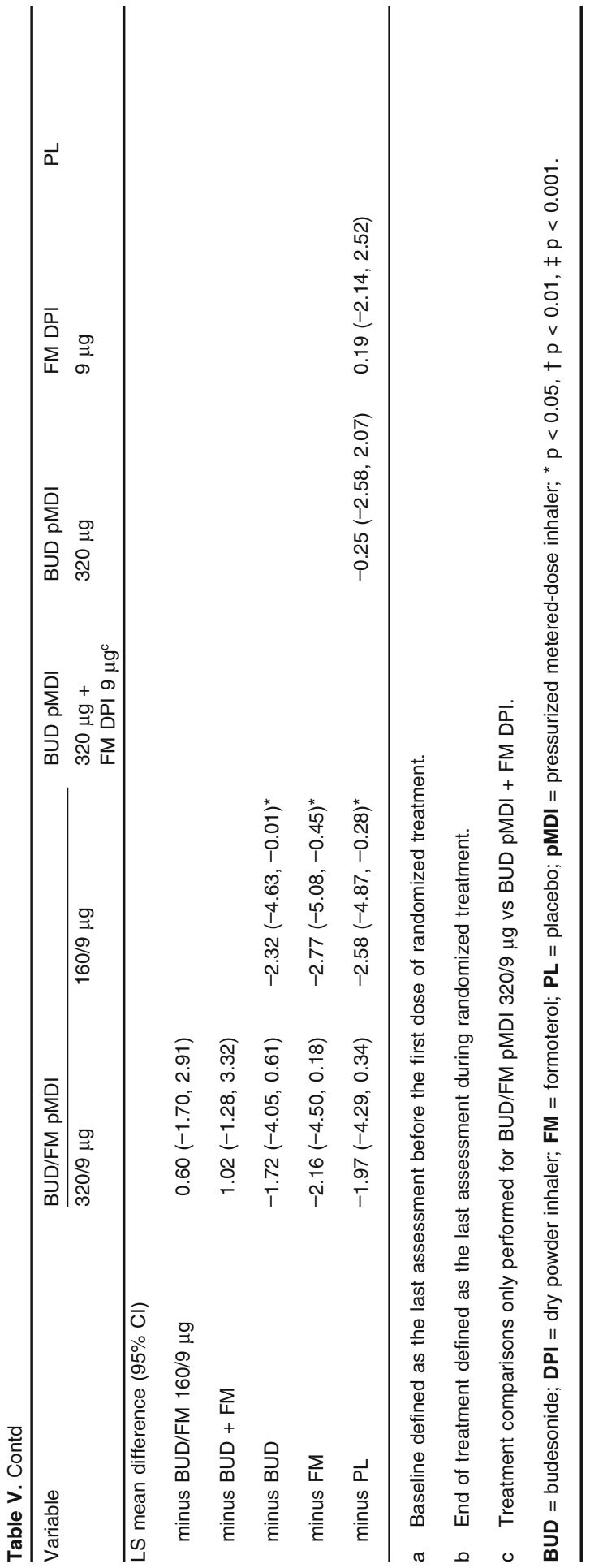

oral candidiasis, bronchitis, sinusitis and diarrhoea. COPD was the most commonly reported $\mathrm{AE}$ and occurred at a higher incidence in the formoterol group $(17.6 \%)$ compared with all other treatment groups $(10.5 \%$ [budesonide plus formoterol] to $13.4 \%$ [budesonide/formoterol $320 / 9 \mu \mathrm{g}$ ]). The percentage of patients with drug-related AEs was low and similar across treatment groups (table VI).

DAEs occurred in 133 patients: $19(6.9 \%)$ in the budesonide/formoterol 320/9 $\mu$ g group, 19 (6.8\%) in the budesonide/formoterol 160/9 $\mu \mathrm{g}$ group, 13 $(4.5 \%)$ in the budesonide plus formoterol group, 25 $(9.1 \%)$ in the budesonide group, $32(11.3 \%)$ in the formoterol group and $25(8.3 \%)$ in the placebo group. The most common DAE was COPD, which occurred at a higher incidence in the budesonide $(5.8 \%)$, formoterol $(7.4 \%)$ and placebo (5\%) groups compared with the budesonide and formoterol combination therapy groups (2.9-3.8\%).

Considering the severity of the COPD population in this study, there were only 11 deaths reported during randomized treatment, all of which were classified as SAEs that were not considered to be related to the study medication. Three deaths occurred in the budesonide/formoterol 320/9 $\mu$ g group (nerve root lesion and metastatic lung cancer; cardiac failure; hip fracture and subsequent cardiopulmonary failure), four in the budesonide/formoterol 160/9 $\mu \mathrm{g}$ group (COPD; cardiac arrest; congestive heart failure and COPD; COPD), two in the budesonide group (COPD; cerebrovascular accident), one in the formoterol group (myocardial infarction) and one in the placebo group (subarachnoid haemorrhage).

The incidence of individual non-fatal SAEs was similar across treatment groups, except for COPD, which was highest in the budesonide/formoterol $320 / 9 \mu \mathrm{g}$ group, lowest in the budesonide and formoterol groups and similar in the budesonide/formoterol 160/9 $\mu \mathrm{g}$, budesonide plus formoterol and placebo groups (table VII). Overall, the most common individual non-fatal SAEs (occurring in at least three randomized patients) were COPD (4.5\%), pneumonia $(0.6 \%)$, atrial fibrillation $(0.5 \%)$, prostate cancer $(0.2 \%)$, congestive heart failure $(0.2 \%)$, 
- BUD/FM pMDI 320/9 $\mu \mathrm{g}$

- BUD/FM pMDI 160/9 $\mu \mathrm{g}$

- BUD pMDI $320 \mu \mathrm{g}+$ FM DPI $9 \mu \mathrm{g}$

- BUD pMDI $320 \mu \mathrm{g}$

* FM DPI $9 \mu \mathrm{g}$

$+\mathrm{PL}$

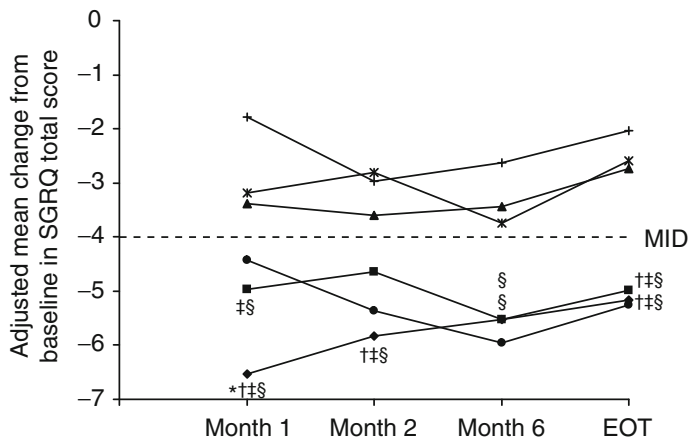

$\begin{array}{lllll}\text { Treatment } & & & \\ \text { BUD/FM pMDI 320/9 } \mu \mathrm{g} & 252 & 242 & 224 & 253 \\ \text { BUD/FM pMDI 160/9 } \mu \mathrm{g} & 257 & 257 & 232 & 262 \\ \text { BUD pMDI 320 } \mu \mathrm{g}+\mathrm{FM} \text { DPI } 9 \mu \mathrm{g} & 260 & 250 & 224 & 263 \\ \text { BUD pMDI 320 } \mu \mathrm{g} & 243 & 222 & 195 & 243 \\ \text { FM DPI 9 } \mu \mathrm{g} & 244 & 232 & 206 & 248 \\ \text { PL } & 254 & 231 & 218 & 254 \\ & & & \end{array}$

Fig. 5. Adjusted mean changes in the St George's Respiratory Questionnaire (SGRQ) total scores from baseline to the end of months 1,2 and 6, and to the last assessment during randomized treatment (end of treatment [EOT]). Baseline was defined as the last assessment before the first dose of randomized treatment. BUD = budesonide; $\mathbf{D P I}=$ dry powder inhaler; $\mathbf{F M}=$ formoterol; $\mathbf{M I D}=$ minimal important difference; $\mathrm{PL}=$ placebo; $\mathbf{p M D I}=$ pressurized metered-dose inhaler; ${ }^{*} p<0.05$ vs BUD pMDI + FM DPI; † $p<0.05$ vs BUD pMDI; $\neq p<0.05$ vs FM DPI; $\S \mathrm{p}<0.05$ vs PL.

respiratory failure $(0.2 \%)$ and acute bronchitis $(0.2 \%)$. The overall incidence of non-fatal SAEs, unadjusted for treatment exposure time, was $11.2 \%$ in the budesonide/formoterol 320/9 $\mu \mathrm{g}$ group, $10.7 \%$ in the budesonide/formoterol 160/9 $\mu \mathrm{g}$ group, $9.1 \%$ in the budesonide plus formoterol group, $9.5 \%$ in the budesonide group, $8.1 \%$ in the formoterol group and $8.3 \%$ in the placebo group.

The incidence of AEs typically associated with local effects of corticosteroids (e.g. candidiasis, voice effects) was highest in the budesonide/formoterol 320/9 $\mu \mathrm{g}$ (6.9\%) and budesonide (5.5\%) groups, and lowest in the budesonide/formoterol $160 / 9 \mu \mathrm{g}$ (3.2\%), budesonide plus formoterol (3.1\%), formoterol $(3.2 \%)$ and placebo $(2.3 \%)$ groups. The incidence of AEs potentially associated with systemic effects of corticosteroids (e.g. bone effects, diabetes control, skin effects, weight gain, ocular effects, taste effects, adrenal suppression) was low, with a similar incidence observed across all treatment groups $(2.8-3.5 \%)$.

Despite the known association of ICSs with pneumonia, ${ }^{[13]}$ there was no difference between treatment groups in the incidence of pneumoniarelated AEs (table VIII). For lung infections other than pneumonia, the incidence was higher in all active treatment groups, except budesonide/formoterol $160 / 9 \mu \mathrm{g}$, compared with the placebo group; these differences were driven largely by bronchitis (table VIII). Two patients had DAEs of pneumonia (one in the budesonide group and one in the placebo group) and 13 patients had pneumonia-related SAEs that occurred during or after the randomized treatment period with no preponderance for any specific treatment group noted (budesonide/formoterol 320/ $9 \mu \mathrm{g}[\mathrm{n}=1]$; budesonide/formoterol 160/9 $\mu \mathrm{g}$ $[\mathrm{n}=3]$; budesonide plus formoterol [ $\mathrm{n}=2]$; budesonide $[\mathrm{n}=3]$; formoterol $[\mathrm{n}=3]$; placebo $[\mathrm{n}=1]$ ). 
Table VI. Commonly reported adverse events (AEs) that were considered to be related to study medication by the investigator and reported by at least three patients

\begin{tabular}{|c|c|c|c|c|c|c|}
\hline \multirow[t]{2}{*}{ Variable } & \multicolumn{2}{|c|}{ BUD/FM pMDI } & \multirow{2}{*}{$\begin{array}{l}\text { BUD pMDI } \\
320 \mu \mathrm{g}+ \\
\text { FM DPI } 9 \mu \mathrm{g} \\
(\mathrm{n}=287)\end{array}$} & \multirow{2}{*}{$\begin{array}{l}\text { BUD pMDI } \\
320 \mu \mathrm{g} \\
(\mathrm{n}=275)\end{array}$} & \multirow{2}{*}{$\begin{array}{l}\text { FM DPI } \\
9 \mu \mathrm{g} \\
(\mathrm{n}=284)\end{array}$} & \multirow{2}{*}{$\begin{array}{l}P L \\
(n=300)\end{array}$} \\
\hline & $\begin{array}{l}320 / 9 \mu \mathrm{g} \\
(\mathrm{n}=277)\end{array}$ & $\begin{array}{l}160 / 9 \mu \mathrm{g} \\
(\mathrm{n}=281)\end{array}$ & & & & \\
\hline Mean exposure [days] (SD) & $166.5(41.3)$ & $168.3(37.7)$ & $164.6(40.3)$ & $157.1(51.3)$ & $156.3(53.2)$ & $150.0(60.2)$ \\
\hline $\begin{array}{l}\text { Patients with } \geq 1 \text { drug-related } \\
A E[n](\%)\end{array}$ & $24(8.7)$ & $24(8.5)$ & $17(5.9)$ & $22(8.0)$ & $22(7.7)$ & $18(6.0)$ \\
\hline Oral candidiasis & $7(2.5)$ & $5(1.8)$ & $4(1.4)$ & $8(2.9)$ & $5(1.8)$ & $4(1.3)$ \\
\hline COPD & $2(0.7)$ & $4(1.4)$ & $1(0.3)$ & 0 & $8(2.8)$ & $3(1.0)$ \\
\hline Dysphonia & $4(1.4)$ & 0 & $1(0.3)$ & $2(0.7)$ & $2(0.7)$ & $1(0.3)$ \\
\hline Headache & $1(0.4)$ & $2(0.7)$ & $1(0.3)$ & $1(0.4)$ & $3(1.1)$ & $2(0.7)$ \\
\hline Pharyngolaryngeal pain & $2(0.7)$ & $1(0.4)$ & 0 & $4(1.5)$ & $2(0.7)$ & 0 \\
\hline Acute bronchitis & $1(0.4)$ & 0 & $1(0.3)$ & 0 & $2(0.7)$ & $1(0.3)$ \\
\hline Dyspnoea & $1(0.4)$ & $1(0.4)$ & 0 & $1(0.4)$ & 0 & $2(0.7)$ \\
\hline Dizziness & $1(0.4)$ & $2(0.7)$ & 0 & 0 & $1(0.4)$ & 0 \\
\hline Muscle spasm & $1(0.4)$ & 0 & $1(0.3)$ & $1(0.4)$ & $1(0.4)$ & 0 \\
\hline Weight increased & 0 & $1(0.4)$ & $1(0.3)$ & $1(0.4)$ & 0 & $1(0.3)$ \\
\hline Cough & 0 & 0 & $1(0.3)$ & 0 & $1(0.4)$ & $1(0.3)$ \\
\hline Diarrhoea & 0 & 0 & $1(0.3)$ & $1(0.4)$ & $1(0.4)$ & 0 \\
\hline Dry mouth & $1(0.4)$ & 0 & $1(0.3)$ & $1(0.4)$ & 0 & 0 \\
\hline Insomnia & 0 & $1(0.4)$ & 0 & $1(0.4)$ & 0 & $1(0.3)$ \\
\hline Palpitation & $1(0.4)$ & 0 & 0 & $1(0.4)$ & $1(0.4)$ & 0 \\
\hline Tremor & 0 & $3(1.1)$ & 0 & 0 & 0 & 0 \\
\hline
\end{tabular}

BUD = budesonide; COPD = chronic obstructive pulmonary disease; DPI = dry powder inhaler; FM = formoterol; PL = placebo; pMDI = pressurized metered-dose inhaler.

The overall incidence of AEs potentially or typically associated with $\beta_{2}$-adrenoceptor agonists effects (i.e. headache, sleep effects, muscle cramps, anxiety, serum potassium decrease, serum glucose increase, palpitation, tremor, tachycardia, agitation) was low (5.9\%), ranging from $4.9 \%$ (budesonide plus formoterol) to $7.5 \%$ (budesonide/formoterol $160 / 9 \mu \mathrm{g}$ ) across treatment groups. The incidence of cardiac-related AEs was slightly higher in the budesonide plus formoterol $(6.6 \%)$ and budesonide (6.5\%) groups compared with the budesonide/formoterol 320/9 $\mu \mathrm{g}(5.1 \%)$, budesonide/formoterol $160 / 9 \mu \mathrm{g}(5.3 \%)$, formoterol $(4.6 \%)$ and placebo (4\%) groups. The most common cardiovascularrelated AEs were hypertension (1.4\%), atrial fibrillation $(0.6 \%)$, angina pectoris $(0.4 \%)$, congestive heart failure $(0.4 \%)$, coronary artery disease $(0.4 \%)$, blood pressure increase $(0.4 \%)$ and myocardial ischaemia $(0.3 \%)$.
Compared with patients in non-US regions, patients enrolled in centres in the US had a higher overall incidence of AEs (63.6\% vs $46.8 \%$ ), a higher overall incidence of AEs per patient-treatment year (3.9 vs 2.0) and a higher incidence of drug-related AEs (13.2\% vs $3.3 \%)$. The incidence of individual AEs generally was similar across the regions.

Clinically significant changes in vital signs, physical examinations or ECG measures were rare, with no clinically important differences observed between the budesonide/formoterol groups and the budesonide, formoterol and placebo groups. There were no clinically important differences between the treatment groups in mean changes from baseline, shifts from baseline or the incidence of clinically important abnormalities for ECG variables.

The observed changes from baseline and differences between the treatment groups in geometric mean 24-hour urinary cortisol (nmol/24 hours) were not considered clinically important. Geometric 
mean 24-hour urinary cortisol values in the formoterol group increased by $30.6 \%$ from baseline at month 6 and by $29.2 \%$ from baseline at end of treatment, while values in the budesonide-containing treatment groups decreased by 23.6-35.8\% from baseline to month 6 and by $24.2-35.8 \%$ from baseline at end of treatment. Treatment with placebo resulted in slight decreases in geometric mean 24hour urinary cortisol at month $6(6.1 \%)$ and end of treatment (7.1\%). Adjusted geometric mean 24-hour urinary cortisol values at months 6 and end of treatment were significantly lower for both budesonide/ formoterol dosage strengths compared with formoterol ( $\mathrm{p} \leq 0.001)$ and for budesonide/formoterol 320/ $9 \mu \mathrm{g}$ and budesonide compared with placebo ( $\mathrm{p} \leq 0.023$ ), and significantly higher for formoterol compared with placebo $(\mathrm{p} \leq 0.038)$. Ten patients had a shift in 24-hour urinary cortisol from normal at baseline to low at end of treatment: four patients in the budesonide/formoterol 320/9 $\mu \mathrm{g}$ group, three in the budesonide plus formoterol group, two in the budesonide group and one in the placebo group.

\section{Discussion}

The results of the present study demonstrated the efficacy of budesonide/formoterol 320/9 $\mu \mathrm{g}$ for both co-primary endpoints (pre-dose $\mathrm{FEV}_{1}$ and 1-hour post-dose $\mathrm{FEV}_{1}$ ) compared with formoterol $9 \mu \mathrm{g}$, budesonide $320 \mu \mathrm{g}$ and placebo in patients with moderate to very severe COPD, indicating the individual contributions of budesonide and formoterol. Budesonide/formoterol 160/9 $\mu \mathrm{g}$ also demonstrated significantly better results on both co-primary endpoints compared with budesonide and placebo, but not compared with formoterol; the latter finding may be related to the substantial efficacy observed with formoterol.

Table VII. Incidence of non-fatal serious adverse events (SAEs) occurring during the randomized treatment period and reported by at least two patients [n (\%)]

\begin{tabular}{|c|c|c|c|c|c|c|}
\hline \multirow[t]{2}{*}{ Adverse event } & \multicolumn{2}{|c|}{ BUD/FM pMDI } & \multirow{2}{*}{$\begin{array}{l}\text { BUD pMDI } \\
320 \mu \mathrm{g}+ \\
\text { FM DPI } 9 \mu \mathrm{g} \\
(\mathrm{n}=287)\end{array}$} & \multirow{2}{*}{$\begin{array}{l}\text { BUD pMDI } \\
320 \mu \mathrm{g} \\
(\mathrm{n}=275)\end{array}$} & \multirow{2}{*}{$\begin{array}{l}\text { FM DPI } \\
9 \mu \mathrm{g} \\
(n=284)\end{array}$} & \multirow{2}{*}{$\begin{array}{l}\mathrm{PL} \\
(\mathrm{n}=300)\end{array}$} \\
\hline & $\begin{array}{l}320 / 9 \mu \mathrm{g} \\
(\mathrm{n}=277)\end{array}$ & $\begin{array}{l}160 / 9 \mu \mathrm{g} \\
(\mathrm{n}=281)\end{array}$ & & & & \\
\hline Patients with $\geq 1 \mathrm{SAE}$ & $31(11.2)$ & $30(10.7)$ & $26(9.1)$ & $26(9.5)$ & $23(8.1)$ & $25(8.3)$ \\
\hline COPD & $17(6.1)$ & $13(4.6)$ & $13(4.5)$ & $10(3.6)$ & $11(3.9)$ & $13(4.3)$ \\
\hline Pneumonia & $1(0.4)$ & $2(0.7)$ & $2(0.7)$ & $3(1.1)$ & $1(0.4)$ & $1(0.3)$ \\
\hline Atrial fibrillation & $1(0.4)$ & $2(0.7)$ & 0 & $2(0.7)$ & $1(0.4)$ & $2(0.7)$ \\
\hline Prostate cancer & $1(0.4)$ & $2(0.7)$ & 0 & 0 & 0 & $1(0.3)$ \\
\hline Acute bronchitis & $1(0.4)$ & $2(0.7)$ & 0 & 0 & 0 & 0 \\
\hline Congestive heart failure & $1(0.4)$ & 0 & 0 & $2(0.7)$ & 0 & 0 \\
\hline Respiratory failure & 0 & $1(0.4)$ & $1(0.3)$ & 0 & $1(0.4)$ & 0 \\
\hline Abdominal pain & 0 & 0 & 0 & $1(0.4)$ & 0 & $1(0.3)$ \\
\hline Acute myocardial infarction & 0 & $1(0.4)$ & 0 & $1(0.4)$ & 0 & 0 \\
\hline Angina pectoris & 0 & 0 & $1(0.3)$ & 0 & $1(0.4)$ & 0 \\
\hline Aortic aneurysm & 0 & $1(0.4)$ & 0 & $1(0.4)$ & 0 & 0 \\
\hline Bronchopneumonia & 0 & $1(0.4)$ & 0 & 0 & $1(0.4)$ & 0 \\
\hline Acute cholecystitis & 0 & 0 & $1(0.3)$ & 0 & 0 & $1(0.3)$ \\
\hline Coronary artery disease & $1(0.4)$ & 0 & 0 & 0 & $1(0.4)$ & 0 \\
\hline Lower limb fracture & 0 & 0 & 0 & $1(0.4)$ & $1(0.4)$ & 0 \\
\hline $\begin{array}{l}\text { Lung squamous cell carcinoma } \\
\text { (stage unspecified) }\end{array}$ & 0 & $1(0.4)$ & $1(0.3)$ & 0 & 0 & 0 \\
\hline Myocardial ischaemia & 0 & 0 & $1(0.3)$ & 0 & 0 & $1(0.3)$ \\
\hline Non-cardiac chest pain & $1(0.4)$ & 0 & 0 & 0 & $1(0.4)$ & 0 \\
\hline Pneumothorax & 0 & 0 & 0 & $2(0.7)$ & 0 & 0 \\
\hline
\end{tabular}

BUD = budesonide; COPD = chronic obstructive pulmonary disease; DPI = dry powder inhaler; FM = formoterol; PL = placebo; PMDI = pressurized metered-dose inhaler 
Table VIII. Adverse events that are potentially related to lung infections [n (\%)]

\begin{tabular}{|c|c|c|c|c|c|c|}
\hline \multirow[t]{2}{*}{ Adverse event } & \multicolumn{2}{|c|}{ BUD/FM pMDI } & \multirow{2}{*}{$\begin{array}{l}\text { BUD pMDI } \\
320 \mu \mathrm{g}+ \\
\text { FM DPI } 9 \mu \mathrm{g} \\
(\mathrm{n}=287)\end{array}$} & \multirow{2}{*}{$\begin{array}{l}\text { BUD pMDI } \\
320 \mu \mathrm{g} \\
(\mathrm{n}=275)\end{array}$} & \multirow{2}{*}{$\begin{array}{l}\text { FM DPI } \\
9 \mu \mathrm{g} \\
(\mathrm{n}=284)\end{array}$} & \multirow{2}{*}{$\begin{array}{l}\mathrm{PL} \\
(\mathrm{n}=300)\end{array}$} \\
\hline & $\begin{array}{l}320 / 9 \mu \mathrm{g} \\
(\mathrm{n}=277)\end{array}$ & $\begin{array}{l}160 / 9 \mu \mathrm{g} \\
(\mathrm{n}=281)\end{array}$ & & & & \\
\hline Pneumonia-related (total) & $3(1.1)$ & $7(2.5)$ & $3(1.0)$ & $5(1.8)$ & $5(1.8)$ & $4(1.3)$ \\
\hline pneumonia & $3(1.1)$ & $6(2.1)$ & $3(1.0)$ & $5(1.8)$ & $3(1.1)$ & $3(1.0)$ \\
\hline bronchopneumonia & 0 & $1(0.4)$ & 0 & 0 & $1(0.4)$ & $1(0.3)$ \\
\hline pneumococcal pneumonia & 0 & 0 & 0 & 0 & $1(0.4)$ & 0 \\
\hline Potential lung infections other than pneumonia (total) & $21(7.6)$ & $9(3.2)$ & $18(6.3)$ & $17(6.2)$ & $13(4.6)$ & $10(3.3)$ \\
\hline bronchitis $^{a}$ & $18(6.5)$ & $8(2.8)$ & $15(5.2)$ & $13(4.7)$ & $11(3.9)$ & $9(3.0)$ \\
\hline lower respiratory tract infection (bacterial) & $2(0.7)$ & $1(0.4)$ & $2(0.7)$ & $1(0.4)$ & $2(0.7)$ & 0 \\
\hline lower respiratory tract infection & $1(0.4)$ & 0 & $1(0.3)$ & 0 & 0 & $1(0.3)$ \\
\hline lower respiratory tract infection (viral) & 0 & 0 & 0 & $2(0.7)$ & 0 & 0 \\
\hline lung infection & 0 & 0 & 0 & $1(0.4)$ & 0 & 0 \\
\hline
\end{tabular}

a The aetiology of 'bronchitis' could be infectious or non-infectious.

BUD = budesonide; $\mathbf{D P I}=$ dry powder inhaler; $\mathbf{F M}=$ formoterol; $\mathbf{P L}=$ placebo; $\mathbf{p M D I}=$ pressurized metered-dose inhaler.

The population of the present study was selected to include patients with moderate to very severe COPD who had experienced exacerbations and were therefore likely to be treated with ICS/LABA combination therapy. Consequently, all patients were current (40-45\% of patients) or previous smokers with a median smoking history of 40 pack-years. This study allowed enrolment of patients with significant co-morbidities, such as hypertension, lipid profile abnormalities, cardiac disease, diabetes, osteoporosis and cataracts, therefore resembling real clinical practice conditions. By allowing patients to receive therapy based on previous treatment during the run-in period, the study was designed to avoid substantial deterioration in COPD symptoms during the run-in period before patients began randomized treatment.

In the present study, treatment with budesonide alone did not improve pre-dose $\mathrm{FEV}_{1}$ or 1-hour post-dose $\mathrm{FEV}_{1}$ compared with placebo. These results are similar to those reported by Calverley et al., ${ }^{[17]}$ who demonstrated no significant improvement in post-dose $\mathrm{FEV}_{1}$ following treatment with budesonide compared with placebo in patients with severe COPD. In contrast, other studies have demonstrated significant improvements in pre- and postdose $\mathrm{FEV}_{1}$ in patients with moderate to very severe COPD receiving budesonide ${ }^{[18]}$ or fluticasone propionate ${ }^{[28,29]}$ alone compared with placebo. These observed differences may be related to the differing methodologies used during the run-in periods of these studies. Previous studies that demonstrated significant improvements from baseline with ICS compared with placebo evaluated pulmonary function using baseline values after a run-in period during which patients received rescue medication alone. ${ }^{[18,28,29]}$ Treatment with rescue medication alone during the run-in period may have affected baseline values and margins for improvement during the randomized treatment period in those studies. In contrast, patients in the present study were generally maintained on their previous therapy, including ICS, because of the widespread availability of long-term maintenance therapies at the time the present study was conducted. Therefore, in the present study, patients received therapy during the run-in period based on their previous treatment to avoid substantial deterioration in COPD symptoms, which may have accounted for the lack of demonstrable effect of budesonide alone on $\mathrm{FEV}_{1}$. However, the significantly greater improvements in pre-dose $\mathrm{FEV}_{1}$ and 1-hour post-dose $\mathrm{FEV}_{1}$ observed with budesonide/formoterol 320/9 $\mu \mathrm{g}$ compared with formoterol in the present study suggest that budesonide in combination with formoterol contributes to improvement in pulmonary function.

The present study is the first to evaluate two dosage strengths of ICS/LABA combination therapy 
in the same study in patients with COPD. The results of direct comparisons demonstrated no significant differences between the two budesonide/formoterol pMDI dosage strengths for any variable. However, some differences were noted between the two budesonide/formoterol dosage strengths with regard to changes from baseline in pulmonary function. In particular, budesonide/formoterol 320/9 $\mu \mathrm{g}$, but not budesonide/formoterol $160 / 9 \mu \mathrm{g}$, resulted in significantly greater improvements from baseline in both pre-dose $\mathrm{FEV}_{1}$ and 1-hour post-dose $\mathrm{FEV}_{1}$ (coprimary efficacy variables) compared with formoterol. Both budesonide/formoterol dosage strengths demonstrated significantly greater improvements from baseline in measures of pulmonary function compared with placebo, and both dosage strengths demonstrated a rapid onset of bronchodilation (within 5 minutes post-dose). However, better maintenance of pulmonary function was observed throughout the study period with budesonide/formoterol 320/9 $\mu \mathrm{g}$ compared with budesonide/formoterol $160 / 9 \mu \mathrm{g}$, as suggested by the changes from baseline in the co-primary efficacy variables and in $\mathrm{FEV}_{1}$ over 12 hours at the end of treatment compared with the day of randomization (figures 3 and 4 , respectively). The differences between the two budesonide/formoterol dosage strengths in their effects on pulmonary function suggest that the dose of ICS influences the efficacy of the combination treatment in this population of patients with moderate to very severe COPD.

Both budesonide/formoterol dosage strengths demonstrated significantly greater improvements in dyspnoea score compared with budesonide, formoterol and placebo in the present study. In addition, both budesonide/formoterol dosage strengths demonstrated significantly greater improvements in almost all other symptom variables compared with budesonide and placebo. In contrast, the monocomponents did not show significant improvements in most symptom variables compared with placebo. Previous studies have also demonstrated significant symptom improvement in patients with COPD treated with budesonide/formoterol DPI 320/9 $\mu \mathrm{g}$ administered twice daily compared with those treated with budesonide ${ }^{[18]}$ or placebo. ${ }^{[17,18]}$ Significantly greater improvements in HR-QOL (based on the SGRQ total score) also were experienced by patients in both budesonide/formoterol pMDI treatment groups compared with patients in the budesonide, formoterol and placebo groups in the present study. Similarly, significant improvements in the SGRQ total score have been reported in patients with COPD treated with budesonide/formoterol DPI 320/ $9 \mu \mathrm{g}$ administered twice daily compared with those treated with the monocomponents ${ }^{[17]}$ or placebo. ${ }^{[17,18]}$ These results indicate that both budesonide and formoterol contribute to the efficacy of the combination product by improving COPD symptoms.

Reductions in exacerbations of $20-25 \%$ were observed for budesonide-containing treatments compared with formoterol and placebo. The magnitude of these reductions in exacerbation rates is similar to that observed in previous studies evaluating the effects of budesonide/formoterol ${ }^{[17,18]}$ or fluticasone propionate/salmeterol. ${ }^{[13,30]}$ Although these previous studies demonstrated statistical significance for this outcome, the present study was not powered to demonstrate differences between treatments for this outcome. The shorter duration of the present study (6 months) compared with previous studies (ranging from 12 months ${ }^{[17,18]}$ to 3 years ${ }^{[13]}$ ) may have contributed to the difference in statistical significance of the exacerbation results between the studies.

Both budesonide/formoterol dosage strengths were well tolerated, with safety profiles consistent with the known safety profiles of budesonide/formoterol in patients with COPD.$^{[17,18]}$ Notably, in this study, the incidence of pneumonia-related AEs, DAEs and SAEs did not differ across treatment groups. These results differ from previous studies in which an increased incidence of pneumonia was associated with fluticasone propionate/salmeterol (500/50 $\mu \mathrm{g}$ twice daily) combination therapy ${ }^{[13,30,31]}$ or fluticasone propionate (500 $\mu \mathrm{g}$ twice daily) alone $^{[13]}$ in patients with COPD. Caution must be used when interpreting the results of the pneumonia data in the present study and in the previous studies, as the diagnosis of pneumonia was generally based 
on clinical judgment, without radiological confirmation in all cases. In the present study, all active treatments, except budesonide/formoterol 160/9 $\mu \mathrm{g}$, exhibited a higher incidence of bronchitis compared with placebo. However, the full clinical characterization of these bronchitic episodes is not clear from the information collected in this study. In addition, there was a slightly higher incidence of non-fatal SAEs in patients receiving budesonide/formoterol compared with budesonide, formoterol and placebo, which may be attributable, in part, to a higher incidence of early discontinuations among patients in the monocomponent and placebo groups.

\section{Conclusions}

The results from the present study indicate that budesonide/formoterol administered via one HFA pMDI is an effective treatment in this population of patients with moderate to very severe COPD. Budesonide/formoterol pMDI 320/9 $\mu \mathrm{g}$ demonstrated significantly greater efficacy for both co-primary endpoints compared with the respective prespecified comparators (formoterol DPI $9 \mu \mathrm{g}$ for pre-dose $\mathrm{FEV}_{1}$ and budesonide pMDI $320 \mu \mathrm{g}$ for 1-hour postdose $\mathrm{FEV}_{1}$ ). Budesonide/formoterol pMDI 160/9 $\mu \mathrm{g}$ demonstrated significantly greater efficacy for 1 hour post-dose $\mathrm{FEV}_{1}$ compared with the prespecified comparator (budesonide pMDI $320 \mu \mathrm{g}$ ). Dyspnoea scores and HR-QOL were significantly improved with both budesonide/formoterol pMDI dosage strengths compared with both monocomponents and placebo. The budesonide-containing treatments also demonstrated numerical reductions in exacerbation rate of 20-25\% compared with formoterol and placebo, although the study was not powered to detect statistical differences for this variable. Both budesonide/formoterol pMDI doses were well tolerated relative to the monocomponents and placebo, with safety findings consistent with the known profiles associated with budesonide and formoterol.

\section{Acknowledgements}

The authors acknowledge Lisa Klumpp, PhD, Cynthia Gobbel, $\mathrm{PhD}$, and Lisa Feder, $\mathrm{PhD}$, from Scientific Connex- ions (Newtown, PA, USA) for writing assistance funded by AstraZeneca LP, the study sponsor, which designed the study and participated in the management, analysis and interpretation of the data, and in the review and approval of the article. Dr Tashkin has served as a consultant for AstraZeneca, Boehringer-Ingelheim, Dey Laboratories and ScheringPlough; received honoraria from AstraZeneca, BoehringerIngelheim and Dey Laboratories; and received or will receive grants from Almirall, AstraZeneca, Boehringer-Ingelheim, Dey Laboratories, Novartis, Pfizer, Sepracor and Forest Laboratories. Dr Rennard has served as a consultant or on the advisory board for Adams, Almirall, Altana, AstraZeneca, Bend, Biolipox, Centocor, Critical Therapeutics, Dey Laboratories, GlaxoSmithKline, ICOS, Johnson \& Johnson, Novartis, Ono Pharma, Perengenix, Pfizer, Roche, Sankyo, Sanofi, Schering-Plough and Talecris; has served as a speaker for AstraZeneca, Boehringer-Ingelheim, GlaxoSmithKline, Otsuka and Pfizer; and has received grants from Almirall, Altana, Astellas, Centocor, GlaxoSmithKline, Nabi, Novartis and Pfizer. Drs Martin, Ramachandran and Goldman and Ms Martin are current employees of AstraZeneca LP and own stock or stock options in AstraZeneca LP. Dr Silkoff is a former employee of AstraZeneca LP.

Investigator List

We thank the following investigators for their participation in the study: René Aalbers, Groningen, the Netherlands; Constantia Abarikwu, Phoenix, AZ, USA; Ishmael Abdullah, Cape Town, South Africa; John Adams, Houston, TX, USA; Jay Adler, Colorado Springs, CO, USA; Tahir Ahmed, Miami Beach, FL, USA; Charles Anderson, Bay Pines, FL, USA; Beata Asankowicz-Bargiel, Ostrow Wielkopolski, Poland; Theo Bantje, Breda, the Netherlands; Halina Batura-Gabryel, Poznan, Poland; George Bensch, Stockton, CA, USA; Henk Berendsen, Den Haag, the Netherlands; William Berger, Mission Viejo, CA, USA; Gary Berman, Plymouth, MN, USA; David Bernstein, Cincinnati, OH, USA; Eugene Bleecker, Winston-Salem, NC, USA; R Block, Terneuzen, the Netherlands; David Boerner, Raleigh, NC, USA; Vinko Bogdanic, Waterloo, IA, USA; Christoph Bolliger, Parow, South Africa; Jerzy Bortkiewicz, Ilawa, Poland; Joseph Boscia, Gaffney, SC, USA; Wesley Bray, Marietta, GA, USA; Shari Brazinsky, San Diego, CA, USA; Walter Dwayne Brown, Lafayette, LA, USA; Krzysztof Brzecki, Turek, Poland; Wissam Chatila, Philadelphia, PA, USA; Kenneth Chinsky, Erie, PA, USA; Teresa Coats, Austin, TX, USA; Stephen Cohen, San Antonio, TX, USA; Gordon Connor, Birmingham, AL, USA; Clinton Corder, Oklahoma City, OK, USA; Henry Covelli, Coeur d'Alene, ID, USA; Jacques Creemers, Eindhoven, the Netherlands; Malgorzata Czajkowska-Malinowska, Bydgoszcz, Poland; Joel Diamond, Pittsburgh, PA, USA; Jan Dindos, Neratovice, Czech Republic; Malgorzata Dobryniewska, Gorzow Wielkopolski, Poland; James Donohue, Chapel Hill, NC, USA; Leonard Dunn, Clearwater, FL, USA; Vincent Duurkens, Nieuwegein, the Netherlands; Andrzej Dymek, Zawadzkie, Poland; David Elkayam, Bellingham, 
WA, USA; Steven Elliott, Evansville, IN, USA; Ingrid Engelbrecht, Pretoria, South Africa; David Erb, Union, SC, USA; Neil Ettinger, Chesterfield, MO, USA; Richard Fei, Lafayette, LA, USA; Barry Feinstein, Richmond, VA, USA; Gregory Feldman, Spartanburg, SC, USA; Charles Fogarty, Spartanburg, SC, USA; Linda Ford, Papillion, NE, USA; Eva Fridrichovska, Praha, Czech Republic; Ashok Fulambarker, Chicago, IL, USA; William Gamel, Austin, TX, USA; Steven Gans, Harderwijk, the Netherlands; Stuart Garay, New York, NY, USA; Adam Gawron, Sopot, Poland; Sherwin Gillman, Orange, CA, USA; Ronald Gilman, Providence, RI, USA; Mark Gotfried, Glendale, AZ, USA; Gregory Gottschlich, Cincinnati, OH, USA; Nicolas Gross, Hines, IL, USA; Elena Guttlerova, Praha, Czech Republic; Martin Hadrava, Cvikov, Czech Republic; Nicola Hanania, Houston, TX, USA; Rafal Harat, Chrzanow, Poland; Milos Havlik, Znojmo, Czech Republic; Vernon Hershberger, Akron, OH, USA; Robert Hewlett, Irvine, CA, USA; David Hill, Westbury, CT, USA; Ira Horowitz, Cherry Hill, NJ, USA; Gary Hunt, Blue Ridge, GA, USA; Sean Hurley, Spokane, WA, USA; Thomas Hyers, St Louis, MO, USA; Jonathan Ilowite, Mineola, NY, USA; Elvis Irusen, Parow, South Africa; Dirkie Jansen Van Rensburg, Witbank, South Africa; Malgorzata Jedrzejczak, Checiny, Poland; Viktor Jensovsky, Lovosice, Czech Republic; David Johnson, Searcy, AR, USA; Glen Journeay, Austin, TX, USA; Tomasz Kachel, Bystra Slaska, Poland; Richard Kahn, Auburn, ME, USA; Piotr Kaminski, Lublin, Poland; Mitchell Kaye, Minneapolis, MN, USA; Edwin Kerwin, Medford, OR, USA; Walter Kleinsteuber, Louisville, KY, USA; Steven Koenig, Charlottesville, VA, USA; Vitezslav Kolek, Olomouc, Czech Republic; Phillip Korenblat, St Louis, MO, USA; Luke Krige, Port Elizabeth, South Africa; Peter Krumpe, Reno, NV, USA; Piotr Kuna, Lodz, Poland; Ritsu Kuno, Richmond, VA, USA; Deepak Lakha, Lenasia, South Africa; David Laman, Jefferson Hills, PA, USA; Tadeusz Latos, Karpacz, Poland; Michael Lawrence, Taunton, MA, USA; Thomas Lemire, Missoula, MT, USA; Wlodzimierz Leszczynski, Gidle, Poland; Bernard Levine, Phoenix, AZ, USA; Michael Littner, Sepulveda, CA, USA; Halina Lupinska, Lomza, Poland; Dorota Malosek, Szczecin, Poland; Michael Mandel, Larchmont, NY, USA; Ebrahim Manuel, Cape Town, South Africa; Jaroslav Mares, Strakonice, Czech Republic; Gregory Mason, Torrance, CA, USA; Dennis McCluskey, Mogadore, OH, USA; Charlene McEvoy, Minneapolis, MN, USA; Barbara McGuire, Albuquerque, NM, USA; Arturo Meade, Fort Smith, AR, USA; Isaac Melamed, Centennial, CO, USA; Mark Millard, Dallas, TX, USA; Brian Miller, Killeen, TX, USA; Martin Mollen, Phoenix, AZ, USA; Timothy Moriarty, Panama City, FL, USA; Piotr Nalepa, Krakow, Poland; Anjuli Nayak, Normal, IL, USA; Heylene Nell, Cape Town, South Africa; Harold Nelson, Denver, CO, USA; Artur Niemiec, Krakow, Poland; Grant Nieuwoudt, Cape Town, South Africa; Michael Noonan, Portland, OR, USA; Marzena Okninska-Wasiak, Siedlce, Poland; Robert Onder Jr, St Louis, MO, USA; Trevenesan
Padayachee, Umkomaas, South Africa; Parimal Parikh, New Orleans, LA, USA; Amit Patel, Riverside, CA, USA; Hana Paukova, Kladno, Czech Republic; James Pearle, Fullerton, CA, USA; Andrew Pedinoff, Skillman, NJ, USA; Piotr Piskorz, Wolomin, Poland; Martin Polasek, Ostrava, Czech Republic; Alexandra Popelkova, Beroun, Czech Republic; Jolana Presperinova, Liberec, Czech Republic; Anna ProkopStaszecka, Krakow, Poland; Krishna Pudi, Simpsonville, SC, USA; Albert Razzetti, DeLand, FL, USA; Marcin Regulski, Otwock, Poland; Pavel Reiterer, Usti nad Labem, Czech Republic; Dennis Riff, Anaheim, CA, USA; Emory Robinette, Abingdon, VA, USA; Cesar Rodarte, Mesa, AZ, USA; Jonathan Rosen, Bristol, CT, USA; Ingrid J. Roux, Cape Town, South Africa; Cezary Rybacki, Bydgoszcz, Poland; Steven Sahn, Charleston, SC, USA; Gilbert Salazar, San Antonio, TX, USA; Jana Satinska, Ostrava, Czech Republic; Eric Schenkel, Easton, PA, USA; Noel Schlösser, Utrecht, the Netherlands; Nathan Schultz, Walnut Creek, CA, USA; Frank Sciurba, Pittsburgh, PA, USA; Peter Sebastian, Durban, South Africa; William Seger, Fort Worth, TX, USA; Allan Seibert IV, Mobile, AL, USA; Sanjay Sethi, Buffalo, NY, USA; Paul Shapero, Bangor, ME, USA; Amir Sharafkhaneh, Houston, TX, USA; Mandy Shaw, Omaha, NE, USA; John Sibille, Sunset, LA, USA; Thomas Siler, St. Charles, MO, USA; Howard Silverboard, Atlanta, GA, USA; Wayne Sinclair, Missoula, MT, USA; Baldev Singh, Pembroke Pines, FL, USA; Henk Sinninghe-Damsté, Almelo, the Netherlands; Emil Skobeloff, Ridley Park, PA, USA; Wojciech Skucha, Proszowice, Poland; Pawel Sliwinski, Warszawa, Poland; Cezary Sosnowski, Bialystok, Poland; John Southard, Council Bluffs, IA, USA; Paul Staab, Marrero, LA, USA; William Stein, Rochester, NY, USA; Mary Strek, Chicago, IL, USA; Luba Strouhova, Kutna Hora, Czech Republic; Clement Strumillo, Las Vegas, NV, USA; Robert Sussman, Summit, NJ, USA; Wojciech Szafranski, Radom, Poland; Martha Tarpay, Oklahoma City, OK, USA; James Taylor, Tacoma, WA, USA; Wanda Terlecka, Czestochowa, Poland; Diego Torres II, Ormond Beach, FL, USA; Stephen Ulrich, Zanesville, OH, USA; Marjo Van De Ven, Arnhem, the Netherlands; Jan Van Noord, Heerlen, the Netherlands; Josef Veverka, Rokycany, Czech Republic; Vladimir Vondra, Praha, Czech Republic; John Weiler, Iowa City, IA, USA; Jan Westerman, Jasper, AL, USA; John Winder, Sylvania, OH, USA; Bret Wittmer, Madisonville, KY, USA; Gary Wohlberg, Bay Shore, NY, USA; Robert Wolfe, Los Angeles, CA, USA; James Wolfe, San Jose, CA, USA; Magdalena Zalecka, Poznan, Poland; Petr Zatloukal, Praha, Czech Republic; Vladimir Zindr, Karlovy Vary, Czech Republic; Dariusz Ziora, Zabrze, Poland; Malgorzata Zurowska-Gebala, Tarnow, Poland.

\section{References}

1. Global Initiative for Chronic Obstructive Lung Disease (GOLD). Global strategy for the diagnosis, management, and prevention of chronic obstructive pulmonary disease: up- 
dated 2007 [online]. Available from URL: http://www. goldcopd.com [Accessed 2008 Feb 12]

2. Aalbers R, Ayres J, Backer V, et al. Formoterol in patients with chronic obstructive pulmonary disease: a randomized, controlled, 3-month trial. Eur Respir J 2002; 19: 936-43

3. Dahl R, Greefhorst LAPM, Nowak D, et al. Inhaled formoterol dry powder versus ipratropium bromide in chronic obstructive pulmonary disease. Am J Respir Crit Care Med 2001; 164: 778-84

4. Mahler DA, Donohue JF, Barbee RA, et al. Efficacy of salmeterol xinafoate in the treatment of COPD. Chest 1999; 115: 957-65

5. Rennard SI, Anderson W, Zuwallack R, et al. Use of a longacting $\beta_{2}$-adrenergic agonist, salmeterol xinafoate, in patients with chronic obstructive pulmonary disease. Am J Respir Crit Care Med 2001; 163: 1087-92

6. Wadbo M, Löfdahl C-G, Larsson K, et al. Effects of formoterol and ipratropium bromide in COPD: a 3-month placebo-controlled study. Eur Respir J 2002; 20: 1138-46

7. Alsaeedi A, Sin DD, McAlister FA. The effects of inhaled corticosteroids in chronic obstructive pulmonary disease: a systematic review of randomized placebo-controlled trials. Am J Med 2002; 113: 59-65

8. Burge PS, Calverley PM, Jones PW, et al. Randomised, double blind, placebo controlled study of fluticasone propionate in patients with moderate to severe chronic obstructive pulmonary disease: the ISOLDE trial. BMJ 2000; 320: 1297-303

9. Gartlehner G, Hansen RA, Carson SS, et al. Efficacy and safety of inhaled corticosteroids in patients with COPD: a systematic review and meta-analysis of health outcomes. Ann Fam Med 2006; 4: 253-62

10. Sin DD, Tu JV. Inhaled corticosteroids and the risk of mortality and readmission in elderly patients with chronic obstructive pulmonary disease. Am J Respir Crit Care Med 2001; 164: $580-4$

11. Sin DD, Man SFP. Inhaled corticosteroids and survival in chronic obstructive pulmonary disease: does the dose matter? Eur Respir J 2003; 21: 260-6

12. Soriano JB, Vestbo J, Pride NB, et al. Survival in COPD patients after regular use of fluticasone propionate and salmeterol in general practice. Eur Respir J 2002; 20: 819-25

13. Calverley PMA, Anderson JA, Celli B, et al., for the TORCH Investigators. Salmeterol and fluticasone propionate and survival in chronic obstructive pulmonary disease. $\mathrm{N}$ Engl $\mathrm{J}$ Med 2007; 356: 775-89

14. Sutherland ER. Inhaled steroids and outcomes in COPD: progressing beyond $\mathrm{FEV}_{1}$. Chest 2007; 131: 648-9

15. Soriano JB, Sin DD, Zhang X, et al. A pooled analysis of FEV 1 decline in COPD patients randomized to inhaled corticosteroids or placebo. Chest 2007; 131: 682-9

16. Halpin D. Mortality in COPD: inevitable or preventable? Insights from the cardiovascular arena. COPD 2008; 5: 187-200

17. Calverley PM, Boonsawat W, Cseke Z, et al. Maintenance therapy with budesonide and formoterol in chronic obstructive pulmonary disease. Eur Respir J 2003; 22: 912-9

18. Szafranski W, Cukier A, Ramirez A, et al. Efficacy and safety of budesonide/formoterol in the management of chronic obstructive pulmonary disease. Eur Respir J 2003; 21: 74-81
19. Eltayara L, Becklake MR, Volta CA, et al. Relationship between chronic dyspnea and expiratory flow limitation in patients with chronic obstructive pulmonary disease. Am J Respir Crit Care Med 1996; 154: 1726-34

20. Miller CJ, Senn S, Mezzanotte WS. Bronchodilation of formoterol administered with budesonide: device and formulation effects. Contemp Clin Trials 2008; 29: 114-24

21. American Thoracic Society. Standardization of spirometry, 1994 update. Am J Respir Crit Care Med 1995; 152: 1107-36

22. Crapo RO, Morris AH, Gardner RM. Reference spirometric values using techniques and equipment that meet ATS recommendations. Am Rev Respir Dis 1981; 123: 659-64

23. Leidy NK, Schmier JK, Jones MK, et al. Evaluating symptoms in chronic obstructive pulmonary disease: validation of the Breathlessness, Cough, and Sputum Scale. Respir Med 2003; 97: S59-70

24. Leidy NK, Wyrwich KW. Bridging the gap: using triangulation methodology to estimate minimal clinically important differences (MCIDs). COPD 2005; 2: 157-65

25. Jones PW, Spencer S, Adie S. The St George's Respiratory Questionnaire manual, Version 2.1. London: Respiratory Medicine, St. George's, University of London, 2003

26. Jones PW, Quirk FH, Baveystock CM, et al. A self-complete measure of health status for chronic airflow limitation. The St George's Respiratory Questionnaire. Am Rev Respir Dis 1992; 145: 1321-7

27. Jones PW. St George's Respiratory Questionnaire: MCID. COPD 2005; 2: 75-9

28. Mahler DA, Wire P, Horstman D, et al. Effectiveness of fluticasone propionate and salmeterol combination delivered via the diskus device in the treatment of chronic obstructive pulmonary disease. Am J Respir Crit Care Med. 2002; 166: 108491

29. Calverley P, Pauwels R, Vestbo J, et al., for the TRISTAN (Trial of Inhaled Steroids and long-acting $\beta_{2}$ agonists) study group. Combined salmeterol and fluticasone in the treatment of chronic obstructive pulmonary disease: a randomised controlled trial. Lancet 2003; 361: 449-56

30. Kardos P, Wencker M, Claab T, et al. Impact of salmeterol/ fluticasone propionate versus salmeterol on exacerbations in severe chronic obstructive pulmonary disease. Am J Respir Crit Care Med 2007; 175: 144-9

31. Wedzicha JA, Calverley PMA, Seemungal TA, et al. The prevention of chronic obstructive pulmonary disease exacerbations by salmeterol/fluticasone propionate or tiotropium bromide. Am J Respir Crit Care Med 2008; 177: 19-2

Correspondence: Dr Donald P. Tashkin, David Geffen School of Medicine at UCLA, Division of Pulmonary and Critical Care Medicine, 10833 Le Conte Avenue, Los Angeles, CA 90095-1690, USA.

E-mail: dtashkin@mednet.ucla.edu 